INRA Prod. Anim.,

2012, 25 (4), 337-350

\title{
Utilisation périphérique du glucose chez le poulet et le canard : implications pour la croissance et la qualité de la viande
}

\author{
N. RIDEAU ${ }^{1}$, S. METAYER-COUSTARD ${ }^{1}$ \\ ${ }^{1}$ INRA, UR83 Recherches Avicoles, F-37380 Nouzilly, France \\ Courriel :Nicole.Rideau@tours.inra.fr
}

\begin{abstract}
Comprendre les mécanismes qui régulent l'utilisation périphérique du glucose est une question centrale pour la maîtrise de la croissance musculaire et de la composition corporelle et au-delà, puisque ces caractères ont des répercussions sur l'efficacité des productions, la quantité de rejets, la qualité nutritionnelle et technologique des produits, les performances de reproduction et la santé.
\end{abstract}

Les Oiseaux ont développé des mécanismes adaptatifs originaux leur assurant un métabolisme énergétique actif caractérisé par une température et une glycémie basales élevées $\left(42^{\circ} \mathrm{C}\right.$ et $2 \mathrm{~g} / \mathrm{L}$ ). Les travaux réalisés en majorité sur les espèces d'intérêt agronomique (poulet, canard) montrent que le métabolisme glucidique des Oiseaux présente des différences notables par rapport aux Mammifères. La première et la plus facilement accessible concerne ainsi la valeur de la glycémie basale, deux fois plus élevée que chez les Mammifères (Hazelwood et Lorenz 1959) même après un jeûne de courte durée (de 1 à 8 jours, Belo et al 1976, Hazelwood 1986) ou avec un régime dépourvu en sucres (Renner et Elcombe 1967). On constate parallèlement que la cellule $\beta$-pancréatique du poulet est, contrairement à celle des Mammifères, relativement peu sensible au glucose in vitro et in vivo (cf. revue de Rideau 1998), ou que des doses massives d'insuline, qui seraient mortelles chez les Mammifères, n'entraînent pas de convulsions hypoglycémiantes chez le poulet (cf. revue de Simon 1989). Cependant, si les Oiseaux sont résistants aux effets hypoglycémiants de l'insuline exogène, ils montrent une sensibilité élevée au glucagon (Hazelwood 1984, Akiba et al 1999).

Les particularités des principaux organes impliqués dans la régulation du métabolisme glucidique chez les Oiseaux ont été passées en revue plus ou moins récemment (Hazelwood 1986, Simon 1989, Rideau 1998, Tesseraud et al 2007, Braun et Sweazea 2008, Rideau et al 2008, Scanes 2009). Certains domaines sont cependant restés longtemps controversés ou demeurent encore énigmatiques. Citons en particulier la première étape limitante de l'utilisation périphérique du glucose impliquant d'une part, la nature encore mal caractérisée des transporteurs de glucose au niveau du muscle et du tissu adipeux et d'autre part, la glucokinase enzyme intracellulaire qui exerce chez les Mammifères un rôle fondamental dans la régulation de l'homéostasie glucidique (Girard et al 1997) longtemps contestée dans l'espèce aviaire. Dans une première partie, nous rapportons quelques données générales concernant les particularités du métabolisme glucidique et de sa régulation par l'insuline dans les espèces avicoles. Dans une deuxième partie, nous présentons les travaux récents concernant la captation de glucose, son utilisation et son stockage par les trois tissus majeurs impliqués dans le maintien de l'homéostasie glucidique à savoir le foie, le muscle et le tissu adipeux. Ces connaissances fondamentales ont pour but d'orienter les programmes de recherche appliquée visant à améliorer la croissance et la qualité des viandes de volailles.

\section{1 / La glycémie et ses varia- tions}

La glycémie des poulets et des canards est, à l'état nourri, en moyenne de 1,90 à 2,20 g/L (Hazelwood 1986, Farhat et Chavez 2000). Des valeurs récentes rapportées chez des poulets de souche «chair» (pour la production de viande) montrent cependant des varia- tions considérables, même à l'état basal, s'étendant entre 1,56 et $3,30 \mathrm{~g} / \mathrm{L}$ sans que l'on puisse imputer ces différences à l'âge des poulets ou à la méthode de mesure de la glycémie (Scanes 2009). Les variations intra- et inter-essais sont très rarement présentées par les auteurs et les variations entre laboratoires ne sont jamais évoquées. Un standard international pour la détermination du glucose chez les Oiseaux serait utile pour suppléer au manque d'étalonnage des techniques (Scanes 2008, 2009).

L'origine génétique des animaux, leur âge et l'état nutritionnel influent sur la glycémie basale. Ainsi, des lignées de poulets sélectionnées sur l'engraissement présentent des glycémies basales significativement différentes (Touchburn et al 1981) ; à l'opposé une sélection sur la glycémie basale a été possible (Leclercq et al 1987). Lu et al 2007 rapportent que la glycémie passe progressivement de $1,16 \mathrm{~g} / \mathrm{L}$ à 10 jours de vie embryonnaire à $2,33 \mathrm{~g} / \mathrm{L} 3$ jours après 1'éclosion tandis que Sinsigalli et al (1987) constatent que la glycémie basale de poulets sélectionnés sur la croissance diminue significativement de 6 à 12 semaines d'âge. Enfin et contrairement aux Mammifères, le jeûne exerce peu ou pas d'effet sur la glycémie (Hazelwood et Lorenz 1959, Belo et al 1976, Harvey et al 1978, Tinker et al 1986), ce que confortent des études récentes réalisées à partir des souches modernes de poulets de chair montrant qu'un jeûne de courte durée diminue systématiquement, quoique relativement peu, la concentration circulante de glucose (Edwards et al 1999, Buyse 
et al 2002, Nijdam et al 2006, Dupont et al 2008, Proszkowiec-Weglarz et al 2009).

\section{2 / Quelques notions géné- rales concernant le métabo- lisme intermédiaire et la régulation de la glycémie}

\section{1 / Modifications du métabo-
lisme intermédiaire de l'em- \\ 2.1 / Modifications du métabo-
lisme intermédiaire de l'em- bryon à l'âge adulte}

\section{Encadré 1. Voies métaboliques d'utilisation du glucose.}

1- Quelle que soit l'espèce animale, la concentration du glucose dans le sang varie peu au cours de la journée (environ $1 \mathrm{~g} / \mathrm{L}$ soit $5 \mathrm{mmol} / \mathrm{L}$ dans la plupart des espèces). Elle fluctue dans des limites relativement étroites $(0,72-3,60 \mathrm{~g} / \mathrm{L}$ soit $4-10 \mathrm{mmol} / \mathrm{L})$ quel que soit l'état nutritionnel (jeûne ou ingestion d'hydrates de carbone même en quantités importantes).

2- Toute modification de glycémie découle d'un déséquilibre entre l'entrée de glucose dans la circulation générale et l'utilisation tissulaire de glucose.

3- L'utilisation du glucose dans les tissus varie selon les conditions physiologiques. À jeun il existe une utilisation constante de glucose dans les tissus consommateurs obligés de glucose (le cerveau, les éléments figurés du sang qui ne peuvent pas utiliser les acides gras pour couvrir leurs besoins énergétiques) ; après une prise alimentaire, l'utilisation du glucose augmente principalement dans les tissus insulinosensibles (muscle squelettique, tissu adipeux). Lors d'un exercice, l'utilisation de glucose augmente de manière indépendante de l'insuline dans le muscle squelettique.

4- Une fois transporté dans les cellules, le glucose peut être stocké sous forme de glycogène ou peut être métabolisé en pyruvate par la voie de la glycolyse. Le glycogène hépatique sert essentiellement à maintenir la glycémie pendant les périodes postprandiales. Le contenu en glycogène du foie est donc très variable. Le glycogène des muscles sert de réserve énergétique et ne participe pas directement à la régulation de la glycémie. Le pyruvate est un substrat situé à un carrefour métabolique : il peut être réduit en lactate, transaminé pour former de l'alanine ou converti en acétyl CoA. L'acétyl CoA est soit oxydé en $\mathrm{CO}_{2}$ et $\mathrm{H}_{2} \mathrm{O}$ dans le cycle de Krebs, soit converti en acides gras par les voies de la lipogenèse.

5- L'utilisation du glucose est régulée spécifiquement selon les tissus (voir tableaux 1 et 2 ).

Figure 1. Voies métaboliques d'utilisation du glucose.

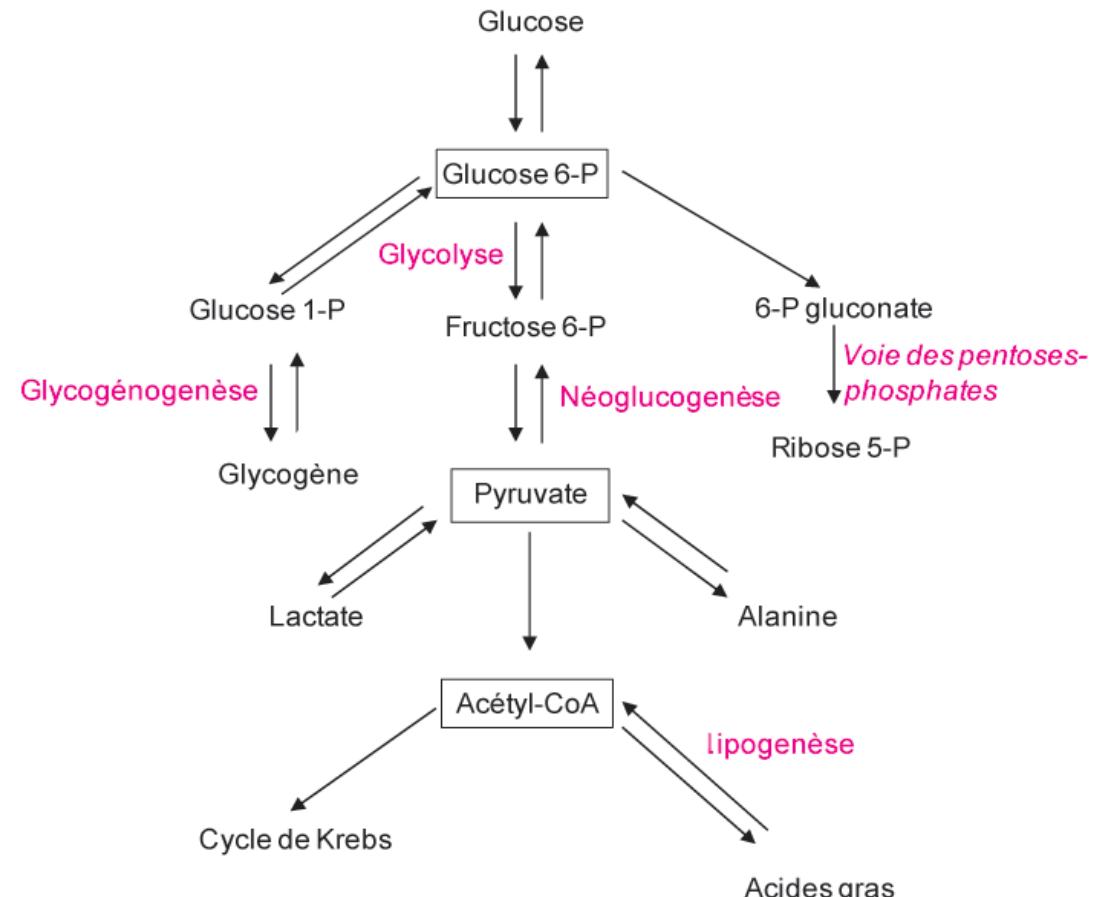

Acides gras la base du poids sec) ; les lipides constituent la principale source d'énergie pour le développement (Moran 2007, de Oliveira et al 2008). En fin de développement, l'embryon utilise une grande partie des lipides pour la néoglucogenèse mais des quantités importantes sont également converties en corps cétoniques pour être utilisés par le cœur, le cerveau et le rein embryonnaires (de Oliveira et al 2008). Le glycérol issu du métabolisme hépatique des triglycérides du jaune est en fin d'incubation, le substrat prédominant pour la synthèse du glycogène hépatique et musculaire (Sunny et Becquette 2011). Entre 15 et 19 jours d'incubation, le foie est le siège d'un métabolisme actif conduisant au transfert de glucose et d'acides gras vers le muscle cervical («pipping muscle») ; celui-ci s'enrichit progressivement en glucose, en glycogène et en protéines en vue de l'éclosion (Pulikanti et al 2010). A la fin de l'incubation, le glycogène joue un rôle vital pour la survie et la qualité de l'embryon. Ainsi, Uni et al (2005) ont montré que l'administration dans l'œuf, à 17,5 jours d'incubation, d'une solution contenant des hydrates de carbone (maltose, sucrose, dextrine) et du beta-hydroxy-beta-methylbutyrate (un métabolite de la leucine) augmente le poids des poussins à l'éclosion de 5 à $6 \%$ par rapport aux contrôles, ainsi que les réserves hépatiques en glycogène (de 2 à 5 fois) et la taille relative du muscle du bréchet (de 6 à $8 \%$ ). Ces performances se sont maintenues jusqu'à la fin de l'essai à 25 jours d'âge. En augmentant la teneur en glycogène hépatique, le traitement in ovo réduit vraisemblablement le besoin de l'embryon en glucose et donc la néoglucogenèse et l'utilisation de protéines musculaires. Zhai et al (2011) ont montré que la nature des sucres ainsi que le volume administrés in ovo influent sur le métabolisme de l'embryon et des poussins à l'éclosion et sur le pourcentage d'œufs fertiles éclos. Les mécanismes moléculaires impliqués dans la transcription des gènes au moment de l'éclosion lors du passage du régime riche en lipides (jaune de l'œuf) au régime riche en hydrates de carbone ont été décrits récemment (Richards et al 2010).

\section{b) Après l'éclosion}

Après 1'éclosion, la glycolyse est favorisée par rapport à la néoglucogenèse (Langslow 1976). Le régime des Oiseaux granivores est constitué majoritairement de céréales apportant les hydrates de carbone sous forme de cellulose et d'amidon. Ce dernier couvre environ 50 à $60 \%$ des besoins énergétiques des volailles. Les molécules d'amidon sont essentiellement hydrolysées par les amylases pancréatiques pour 
donner naissance à des dextrines puis, à du maltose qui est rapidement dégradé par les enzymes intestinales (maltase et isomaltase) en glucose absorbé et transféré au foie via la veine porte. Approximativement $30 \%$ des hydrates de carbone ingérés sont convertis en lactate au niveau de la paroi intestinale (Riesenfeld et al 1982). L'utilisation du glucose varie en fonction de l'âge. En mesurant l'oxydation du glucose par des poulets mis en chambre respiratoire, Buyse et al (2004) ont montré que les jeunes poussins utilisent la majeure partie du glucose ingéré pour la synthèse de glycogène et d'acides aminés non essentiels. A l'opposé, en fin de croissance (5-6 semaines d'âge), les poulets oxydent la majeure partie du glucose ingéré à des fins énergétiques. Cette période est caractérisée par une augmentation exponentielle du dépôt adipeux.

Les voies métaboliques identifiées chez les Mammifères sont, dans l'ensemble, opérationnelles chez les Oiseaux avec des variations quantitatives mais aussi qualitatives ainsi que des différences dans la contribution relative de certaines voies (Stevens 2004). Le foie par exemple est le site principal de la lipogenèse chez les Oiseaux (Leveille et al 1968, Griffin et al 1992) contrairement aux rongeurs ou aux porcs pour lesquels la synthèse des lipides a lieu dans le foie et le tissu adipeux (Hanson et Ballard 1967, Mourot et Kouba 1999). La forme hépatique de la pyruvate kinase (L-PK) présente chez les mammifères n'est pas retrouvée dans le foie du poulet qui n'exprime que l'isoforme M (Strandholm et al 1975). La voie des des pentoses phosphates est peu active chez les Oiseaux (Goodridge 1987). La néoglucogenèse a lieu dans le foie et les reins (avec un rapport de 70/30) alors qu'elle a lieu principalement dans le foie chez les Mammifëres et la phosphoénolpyruvate carboxykinase (PEPCK) présente une distribution intracytoplasmique différente de ceux-ci (Watford et al 1981).

\section{2 / Régulation de la glycé- mie par les hormones pancréa- tiques}

La glycémie des poulets et des Oiseaux en général, dépend de l'insuline à l'état nourri et du glucagon à l'état à jeun. Le rôle critique de l'insuline a été démontré après pancréatectomie quasitotale ou après immunoneutralisation (cf. revue de Simon 1989, Dupont et al 2008). Ces interventions entraînent une hyperglycémie marquée. Le rôle du glucagon est mis en évidence par le fait que des poulets à jeun et pancréatectomisés développent une hypoglycémie. Des résultats semblables ont été obtenus chez le canard (revue de Simon 1989).
Dans ce paragraphe, nous développons certains aspects particuliers de la physiologie de l'insuline qui est mieux connue que celle du glucagon.

\section{a) Sécrétion d'insuline}

Le contrôle de la sécrétion d'insuline a fait l'objet de plusieurs synthèses (Hazelwood 1984, Rideau 1988, Rideau 1998). Alors que chez les Mammifères le glucose est le régulateur physiologique primordial de la sécrétion d'insuline, l'effet insulinotrope du glucose est moins évident chez les Oiseaux. King et Hazelwood (1976) ont montré à l'aide du système pancréatico-duodénal isolé et perfusé de poules adultes que la cellule $\beta$-pancréatique est relativement insensible au glucose. Cette insensibilité, confirmée chez des poulets plus jeunes et chez le canard, a été étendue à d'autres nutriments énergétiques tels que le D-glycéraldéhyde, la leucine ou l' $\alpha$-cétoisocaproate de sodium $(\alpha-$ KIC) connus pour être de puissants initiateurs de la sécrétion d'insuline chez les Mammifères, mais qui se sont révélés inefficaces chez le poulet (Rideau 1998). La cellule $\beta$-pancréatique de poulet reste toutefois sensible aux agents dépolarisants (tels que le $\mathrm{K}+$ ), au tolbutamide (actif sur la fermeture des canaux K + ATP dépendants) et aux agents potentialisateurs de la sécrétion d'insuline (tels que l'acétylcholine ou l'AMPc). L'absence d'effet insulinotrope de la leucine ou de l' $\alpha$-KIC dont le métabolisme est uniquement mitochondrial, suggère qu'il existe dans la cellule $\beta$ une modification du métabolisme du glucose située au-delà du pyruvate. Rappelons que, contrairement aux Mammifères, le pancréas endocrine des Oiseaux est caractérisé par la présence de deux types d'îlots de Langerhans (les îlots- $\beta$ à insuline et les îlots- $\alpha$ à glucagon). Les connaissances relatives au fonctionnement de ces îlots de Langerhans sont encore très parcellaires en raison des difficultés techniques pour aborder ce tissu (Ruffier et al 1998). Récemment, Datar et Bhonde (2006) ont publié une méthode d'isolement d'îlots$\beta$ à partir du pancréas de poulets âgés de 5 ou 6 jours. Cette méthode devrait permettre d'apporter des informations sur les particularités du métabolisme du glucose à l'intérieur de la cellule $\beta$-pancréatique aviaire. Une autre particularité des Oiseaux concerne la résistance des cellules $\beta$-pancréatiques aux drogues diabétogènes. Chez les Mammifères, la destruction chimique des cellules $\beta$-pancréatiques à l'aide d'alloxane ou de streptozotocine (STZ) conduit au diabète, contrairement à ce qui a été rapporté dans diverses espèces aviaires (poulet, canard, hibou) chez lesquelles ces cytotoxines n'exercent aucun effet sur la glycémie (cf. revues de Rideau 1988, Braun et Sweazea 2008). La différence de sensibilité à la STZ pourrait résulter d'un potentiel de défense antioxydant plus élevé dans les îlots de poulet comparés aux îlots de rongeurs (Modak et al 2007).

\section{b) Action de l'insuline}

Comme chez les Mammifères, l'insuline exerce chez le poulet des effets anaboliques sur les différents métabolismes : transport et utilisation de glucose, synthèse de glycogène, contrôle du niveau des enzymes lipogéniques, transport d'acides aminés et synthèse de protéines (cf. revues de Simon 1989, Tesseraud et al 2007). L'insuline stimule également la croissance et la division

\section{Encadré 2. L'insuline est essentielle pour maintenir l'homéostasie du glucose.}

1- L'équilibre entre le stockage du glucose et sa production joue un rôle fondamental pour le maintien de l'homéostasie glucidique. II dépend principalement de la régulation de l'activité et de l'expression des enzymes clé de la glycolyse, de la lipogenèse et de la néoglucogenèse par des facteurs nutritionnels et hormonaux. Les hormones pancréatiques, insuline et glucagon, exercent un rôle majeur dans le contrôle de ces voies métaboliques.

2- Le glucose est le régulateur principal de la sécrétion d'insuline.

- À l'état nourri, l'augmentation de la concentration plasmatique d'insuline entraîne d'une part, une augmentation de l'utilisation de glucose par les tissus insulinosensibles (muscles et tissus adipeux) et d'autre part, une diminution de la production de glucose (en bloquant la synthèse d'enzymes clés de la néoglucogenèse) et une augmentation de la synthèse de glycogène et de lipides par le foie. L'insuline favorise l'entrée du glucose dans les cellules en augmentant le nombre de transporteurs de glucose (GLUT) dans la membrane plasmatique des cellules. L'insuline stimule la synthèse de la glycogène-synthase, ainsi que celles de plusieurs enzymes de la glycolyse. Enfin, l'insuline est une hormone anabolique qui favorise la synthèse des lipides à partir du glucose (entres autres en activant l'acétyl-CoA carboxylase et par une mobilisation accrue de NADPH $+\mathrm{H}+$ ) et inhibe la dégradation des acides gras.

- À jeun, la diminution de la concentration plasmatique d'insuline et l'augmentation de la concentration plasmatique de glucagon s'accompagnent d'une part, d'une diminution de l'utilisation de glucose par certains tissus comme les muscles oxydatifs en vue d'épargner le glucose pour les organes qui en sont strictement dépendants (cerveau, rétine, médullosurrénale...) et d'autre part, d'une augmentation de la production hépatique de glucose par la voie de la glycogénolyse et de la néoglucogenèse. 
Encadré 3. Voies de signalisation intracellulaires de l'insuline chez les Mammifères.

1- L'insuline exerce un nombre important d'effets différents grâce à sa liaison à ses récepteurs spécifiques.

2- Le récepteur à l'insuline (IR) est une protéine héterotétramérique composée de deux sous-unités $\alpha$ extramembranaires et de deux sous-unités $\beta$ transmembranaires. La liaison de l'insuline à la sous-unité $\alpha$ de son récepteur entraîne l'activation de l'activité tyrosinekinase intrinsèque de la sous-unité $\beta$, et l'activation de cascades de signalisation intracellulaire.

3- II existe schématiquement deux grandes voies d'activation intracellulaire après la liaison de l'insuline à son récepteur.

- La première voie est celle de la cascade «Mitogen-Activated Protein Kinase» (MAPK) Dans cette voie, l'association du récepteur de l'insuline avec les protéines Shc et Grb2 provoque une cascade de phosphorylations aboutissant à l'activation de MEK, de MAPK puis des molécules (JNK, Erk1/2 et p38) impliquées dans la prolifération cellulaire et l'apoptose.

- La seconde voie est celle liée à I'«Insulin Receptor Substrates» (IRS). Les IR transphosphorylent plusieurs substrats dont l'IRS 1 à 6 . Cette première série d'évènements aboutit à l'activation en aval d'autres molécules de signalisation comme la PI3-kinase (PI3K). Cette dernière est une enzyme clé dans le métabolisme de l'insuline. Elle a pour rôle la formation de seconds messagers, des phospholipides appelés phosphoinositols triphosphates (PIP3). Ces phospholipides activent de nouvelles sérines/thréonines kinases dont le résultat est l'activation de l'enzyme Akt. L'Akt activée joue un rôle central dans le métabolisme tissulaire, régulant en particulier la translocation de GLUT4. Ainsi, la cascade de signalisation intracellulaire PI3-kinase/Akt conduit à la translocation de GLUT4 du compartiment cytoplasmique vers la membrane, permettant l'augmentation de la captation de glucose par la cellule. L'inactivation de la Glycogène Synthase Kinase-3 (GSK3), après sa phosphorylation par Akt, mène à la déphosphorylation et à l'activation de la Glycogène Synthase (GS) et par conséquent à une accélération de la synthèse de glycogène. Cette seconde voie a été appelée la voie du signal métabolique pour son rôle dans le contrôle des métabolismes protéique, glucidique et lipidique.

cellulaire et inhibe l'apoptose. Le poulet présente toutefois une diminution de la sensibilité à l'insuline exogène par rapport aux mammifères : des doses massives d'insuline, qui seraient mortelles chez ces derniers, n'entraînent pas de convulsions hypoglycémiantes chez le poulet (la plupart des essais ont été réalisés avec une insuline hétérologue

de Mammifères, (cf. revue de Simon 1989). En outre, des concentrations élevées d'insuline n'induisent qu'un captage limité de 2-désoxyglucose par différents muscles ou par le tissu adipeux (Tokushima et al 2005). Une augmentation de la sensibilité à l'insuline exogène a toutefois été rapportée dans les premiers jours qui suivent l'éclosion des

Figure 2. Voies de signalisation intracellulaires de l'insuline chez les mammifères (adapté de Dupont et al 2009).

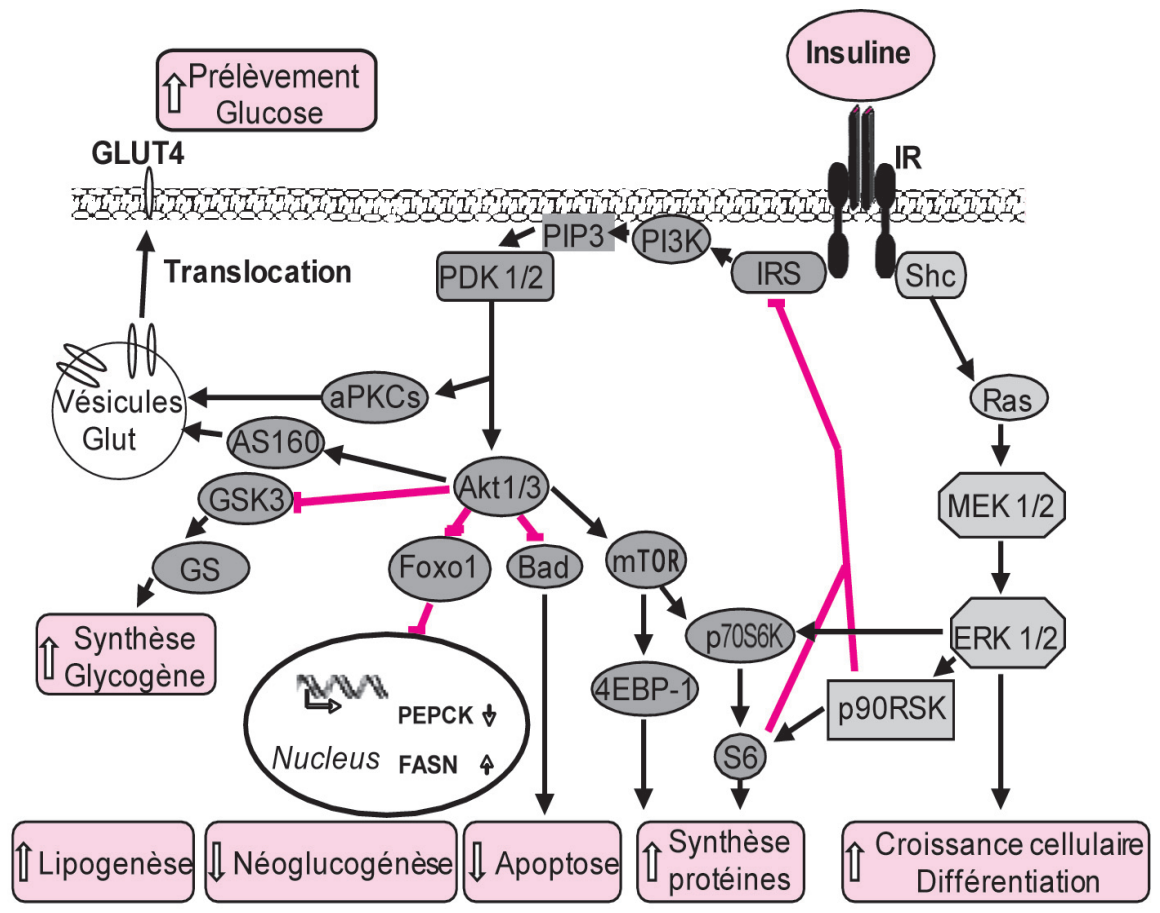

poussins (quel que soit leur type : œuf ou viande) alors que les poulets plus âgés sont caractérisés par une résistance relative à l'insuline exogène (Joseph et al 1996). La réponse au glucagon est par ailleurs atténuée pendant les deux premières semaines de vie postnatale par rapport à des poulets âgés de quatre semaines (Joseph et al 1996). Cette différence de sensibilité liée à l'âge pourrait être induite en partie par les modifications hormonales survenant au moment de l'éclosion, incluant les autres hormones métaboliques telles que les hormones thyroïdiennes (thyroxine et tri-iodothyronine) et les hormones de croissance (hormone de croissance, IGF).

Les voies de signalisation de l'insuline (figure 2) ont été largement étudiées notamment via un modèle «d'insulinopénie» aiguë induite par immuno-neutralisation chez des poulets nourris. Ce modèle a permis de confirmer des résultats antérieurs montrant que les éléments précoces de la voie de signalisation de l'insuline sont présents dans le muscle. De façon paradoxale et à l'inverse de ce qui est observé dans le foie (et à la différence des Mammifères), le niveau d'activation de ces éléments en amont de la cascade insulinique n'est pas modifié dans le muscle dans diverses conditions inhibitrices ou stimulantes alors que les étapes ultérieures sont régulées (Dupont et al 2008). Ainsi, les premiers éléments de la cascade insulinique (phosphorylation sur tyrosine du récepteur et de son substrat IRS-1 et activité PI3K) sont fortement inhibés, dès $1 \mathrm{~h}$ après une injection d'anticorps anti-insuline, dans le foie mais pas dans le muscle. Récemment, les éléments de la cascade de signalisation insulinique ont été caractérisés dans le tissu adipeux de poulet et leur régulation a été évaluée (Dupont et al 2012). Ces études mettent en évidence une apparente résistance du tissu adipeux à l'insuline (cf. $\S 3.3$ ).

\section{3 / Utilisation du glucose par les organes périphériques}

L'entrée du glucose dans les tissus via des transporteurs de glucose à diffusion facilitée (GLUT), son utilisation comme principale source d'énergie par les cellules (glycolyse) ou son stockage sous forme de glycogène dans le foie principalement et dans le muscle, et de lipides dans le foie et le tissu adipeux sont les processus biologiques majeurs qui contrôlent l'homéostasie glucidique. Dans cette partie, nous décrivons quelques aspects nouvellement établis concernant la première étape de l'utilisation du glucose incluant son transport dans la cellule par les transporteurs du glucose (tableau 1, figure 3 ) et sa phosphorylation par les hexokinases 
Tableau 1. Les 3 classes de transporteurs de glucose à diffusion facilitée (état des connaissances chez les Mammifères).

\begin{tabular}{|c|c|c|c|c|}
\hline GLUT & $\mathrm{Km}$ & Tissu & Particularité & Spécificité \\
\hline \multicolumn{5}{|c|}{ Classe 1} \\
\hline GLUT 1 & $5 \mathrm{mM}$ & Ubiquitaire, hématies & $\begin{array}{l}\text { Régule le niveau basal } \\
\text { de glucose }\end{array}$ & Glucose/galactose \\
\hline GLUT 3 & $\begin{array}{l}1 \mathrm{mM} \\
\text { (forte affinité) }\end{array}$ & Neurones & & Glucose/galactose \\
\hline GLUT 4 & $5 \mathrm{mM}$ & Muscles, graisse & $\begin{array}{l}\text { Translocation régulée } \\
\text { par l'insuline }\end{array}$ & Glucose/ pas galactose \\
\hline GLUT 2 & $\begin{array}{l}11 \mathrm{mM} \\
\text { (faible affinité) }\end{array}$ & $\begin{array}{l}\text { Intestin, reins, foie, } \\
\text { cellule } \beta \text {-pancréatique }\end{array}$ & $\begin{array}{l}\text { Captation et efflux de } \\
\text { glucose }\end{array}$ & $\begin{array}{l}\text { Glucose/galactose/ } \\
\text { fructose }\end{array}$ \\
\hline \multicolumn{5}{|c|}{ Classe 2} \\
\hline GLUT 5 & $6 \mathrm{mM}$ & Intestin, sperme & $\begin{array}{l}\text { Tissus métabolisant } \\
\text { le fructose }\end{array}$ & Fructose/(glucose) \\
\hline GLUT 7 & $0,3 \mathrm{mM}$ & Intestin & Sur la membrane apicale & $\begin{array}{l}\text { Glucose/fructose/ } \\
\text { pas galactose }\end{array}$ \\
\hline GLUT 9 & $0,3 \mathrm{mM}$ & Reins, foie & $\begin{array}{l}\text { Colocalise avec GLUT } 2 \\
\text { dans le foie mais pas } \\
\text { dans les reins }\end{array}$ & $\begin{array}{l}\text { Glucose/fructose/ } \\
\text { pas galactose }\end{array}$ \\
\hline GLUT 11 & $0,2 \mathrm{mM}$ & $\begin{array}{l}\text { Muscle, cœur, graisse, } \\
\text { placenta, reins, pancréas }\end{array}$ & $\begin{array}{l}3 \text { isoformes }(A, B, C), \\
\text { répartition différant selon } \\
\text { les tissus }\end{array}$ & $\begin{array}{l}\text { Glucose/fructose/ } \\
\text { pas galactose }\end{array}$ \\
\hline \multicolumn{5}{|c|}{ Classe 3} \\
\hline GLUT 6 & Forte affinité & Cerveau, rate & & Glucose? \\
\hline GLUT 8 & $2,4 \mathrm{mM}(2 \mathrm{DG})$ & $\begin{array}{l}\text { Testicules, cerveau, } \\
\text { graisse, foie, rate }\end{array}$ & & Glucose (fructose) \\
\hline GLUT 10 & $0,3 \mathrm{mM}(2 \mathrm{DG})$ & Cœur, poumons & & $\begin{array}{l}\text { Glucose/galactose/ } \\
\text { pas fructose }\end{array}$ \\
\hline GLUT 12 & 4-5 mM & Tissus insulino-sensibles & & $\begin{array}{l}\text { Glucose/galactose/ } \\
\text { fructose }\end{array}$ \\
\hline
\end{tabular}

Chez les Mammifères, 12 transporteurs de glucose à diffusion facilitée sont décrits à ce jour (Manolescu et al 2007). Ils présentent des affinités variables pour le glucose et des distributions tissulaires différentes. Ils sont répartis en 3 classes (symbole du gène : SCL2A, de la protéine : GLUT).

Classe 1 (GLUT - 1 à - 4): Les plus largement caractérisés en termes de structure, de fonction et de distribution cellulaire.

Classe 2 (GLUT - 5, - 7, - 9 et - 11) : Tous transportent le glucose et le fructose avec un Km < $1 \mathrm{mM}$ (sauf le GLUT5). Aucun n'a été caractérisé de façon fonctionnelle.

Classe 3 (GLUT - 6, - 8, - 10 et - 12): Peu d'informations concernant l'activité fonctionnelle des protéines de cette classe. Les 3 transporteurs sont fonctionnels pour le glucose.

Chez le poulet, 9 transporteurs de glucose à diffusion facilitée ont été identifiés (Hutchinson et al 2008).

(tableau 2). Nous examinons également l'étape de stockage du glucose sous forme de glycogène ou de triglycéride dans les trois types de tissus.

\section{1 / Première étape de la glyco- lyse : transport et phosphoryla- tion du glucose}

\section{a) Dans le foie}

Le glucose traverse la membrane de l'hépatocyte à l'aide de transporteurs de glucose facilités (GLUT-2). Des gènes codant pour les isoformes du transporteur de glucose (GLUT-1 et -2) ont été identifiés dans le foie de poulets de chair (Wang et al 1994, Kono et al 2005). La protéine GLUT-1 n'est cependant pas détectable dans le foie des poulets, suggérant qu'elle n'est pas un transporteur important pour ce tissu (Carver et al 2001). Des niveaux faibles d'ARNm codant pour les transporteurs GLUT-3 et GLUT-8 ont également été détectés dans le foie de poulets de chair (Kono et al 2005).

L'isoforme HK IV ou glucokinase (GK) joue chez les mammifères un rôle unique dans le métabolisme du glucose en contrôlant sa phosphorylation et ainsi, la première étape du métabolisme intracellulaire du glucose. Le rôle clé de la GK dans la régulation de la sécrétion d'insuline par les cellules $\beta$-pancréatiques et dans l'utilisation hépatique du glucose a été largement décrit (cf. revues récentes de Agius 2008, Iynedjian 2009, Matschinsky 2009). L'existence d'une protéine et d'une activité de type GK chez les Oiseaux a longtemps été controversée (Cardenas et al 1998), principalement pour des raisons d'ordre méthodologique ne permettant pas de différencier une activité de type GK des autres activités hexokinases (cf. revue de Berradi et al 2004). Bien qu'un gène de GK n'ait pas été identifié dans le génome du poulet (http://www.ensembl.org/
Gallus gallus), il a été possible de caractériser à partir de foie de poulet un fragment partiel d'ADNc (1326 paires de bases) qui présente une homologie élevée avec l'ADNc de la GK humaine (Berradi et al 2005), une protéine immunoréactive de type GK ainsi qu'une activité de type GK. L'expression du gène, la protéine et l'activité de type GK augmentent en réponse à un repas (Rideau et al 2008) et dépendent de l'insuline à l'état nourri (Dupont et al 2008). L'activité de la GK apparaît 10 fois plus faible dans le foie de poulet, de pigeon ou de canard que dans celui des Mammifères (rongeurs, homme) (Rideau et al 2008), ou de la truite (Panserat et al 2000). Le rôle fonctionnel de la GK chez le poulet a été étudié à l'aide d'un activateur de glucokinase (GKA, RO0281675), (Rideau et al 2010). Cette molécule, administrée par voie orale à des poulets nourris ad libitum, induit une diminution très significative et dose dépendante de la glycémie qui, 
Figure 3. Transport du glucose en fonction de la constante de Michaelis, $\mathrm{Km}$. Le glucose pénètre dans les cellules par diffusion facilitée à travers des protéines transmembranaires (GLUT). L'expression de ces transporteurs est spécifique selon les tissus et leurs caractéristiques leur confèrent un métabolisme du glucose spécifique. La constante $\mathrm{Km}$ est la constante de vitesse de la réaction, elle caractérise l'affinité de l'enzyme pour son substrat.

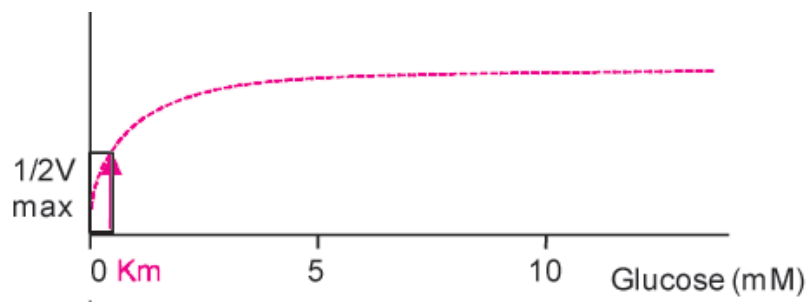

GLUT1, GLUT3

SNC, placenta, cellules sanguines, etc.

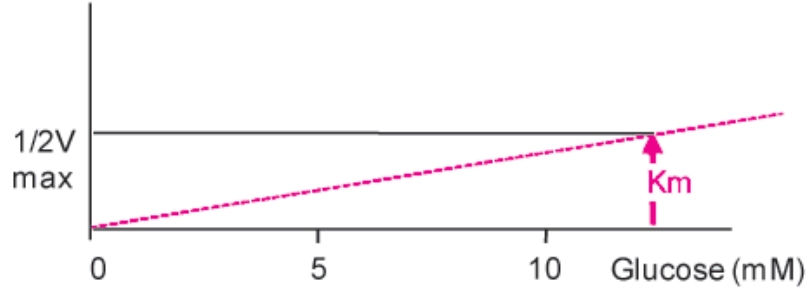

GLUT2

Cellules $\beta$ du pancréas, foie, cellules hypothalamiques spécialisées

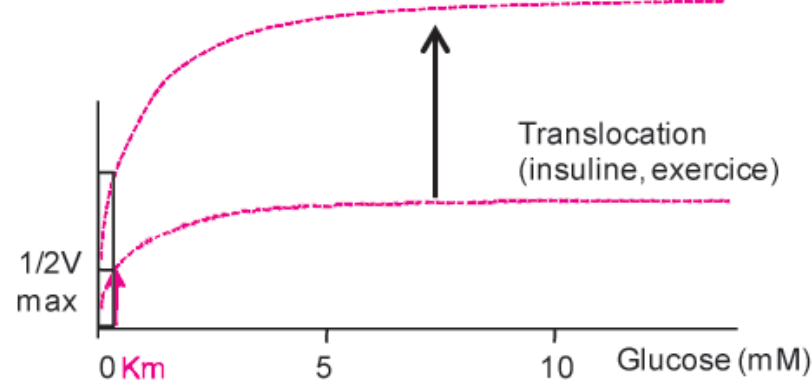

GLUT4

Muscle, tissu adipeux

90 min après administration, chute de 40 à $50 \%$ chez des poulets alimentés et de $13 \%$ chez des poulets à jeun, sans augmentation évidente de l'insulinémie,

contrairement aux rongeurs (Grimsby et al 2003). Cette étude montre que la glucokinase est impliquée dans la régulation de la glycémie du poulet. Les

Tableau 2. Propriétés biochimiques et localisation des 4 isoformes d'hexokinase chez les Mammifères.

\begin{tabular}{|l|c|c|c|c|}
\hline & HKI & HKII & HKIII & HKIV (GK) \\
\hline Poids moléculaire (kDa) & 100 & 100 & 100 & 50 \\
\hline Distribution tissulaire & $\begin{array}{c}\text { Cerveau } \\
\text { reins }\end{array}$ & $\begin{array}{c}\text { Muscle } \\
\text { tissu adipeux }\end{array}$ & $\begin{array}{c}\text { Poumons } \\
\text { rate }\end{array}$ & $\begin{array}{c}\text { Foie } \\
\text { pancréas }\end{array}$ \\
\hline Km glucose (mM) & 0,030 & 0,300 & 0,003 & 6 \\
\hline Km ATP (mM) & 0,5 & 0,7 & 1,0 & 0,6 \\
\hline Ki Glc-6-P (mM) & 0,21 & 0,16 & 0,92 & 60 \\
\hline Régulation par l'insuline & - & + & $?$ & + \\
\hline Liaison mitochondriale & + & + & - & - \\
\hline
\end{tabular}

Une fois dans la cellule, le glucose est immédiatement converti en glucose-6phosphate par l'hexokinase (HK), enzyme cytosolique qui catalyse la réaction de phosphorylation des hexoses sur leur carbone 6. Chez les Mammifères, les caractéristiques biochimiques ont permis d'identifier 4 isoformes différentes HKI, HKII, HKIII et HKIV (Kanno 2000, Wilson 2003). On distingue les tissus glucosensibles (le foie et le pancréas endocrine) et les tissus insulinosensibles (les muscles et le tissu adipeux). Ces deux types de tissus sont caractérisés par la présence d'un couple spécifique (GLUT 2 et HKIV pour les premiers et GLUT4 et HKII pour les seconds) dont les propriétés particulières et non symétriques permettent une régulation coordonnée des flux de glucose dans l'organisme. L'étape limitante de l'utilisation du glucose est régulée par HKIV dans les tissus glucosensibles et par GLUT 4 dans les tissus insulinosensibles.

Abréviations : Glc-6P, glucose -6-phosphate ; HK, hexokinase.

D'après Ureta et al 1987 ; Cardenas et al 1998 ; Wilson 2003.

Voir aussi le site d'accès libre NCBI (http://www.ncbi.nlm.nih.gov/) auteurs suggèrent que la glycémie élevée du poulet pourrait être liée à la faible activité de la GK hépatique. Aux doses les plus élevées, le GKA diminue de façon significative, tardive et transitoire la prise alimentaire avec un effet maximal $3 \mathrm{~h}$ après administration. Les mécanismes impliqués ne sont pas élucidés.

\section{b) Dans le muscle}

Dans le muscle, l'entrée de glucose, étape limitante, est régulée par un transporteur spécifique insulino-sensible (GLUT-4) qui, en réponse à l'insuline ou à une contraction musculaire, migre depuis des vésicules intracellulaires vers la membrane plasmique. Tout changement dans l'expression et/ou l'activité des GLUTs (en particulier GLUT-4) dans le muscle peut modifier la répartition des nutriments et le métabolisme cellulaire et affecter ainsi la qualité des produits. A ce jour, seules 3 isoformes de GLUT ont été identifiées dans le muscle de poulet (GLUT-1 ; -3 et -8) (Seki et al 2003, Kono et al 2005). L'existence d'un transporteur GLUT-4 chez les oiseaux reste controversée (Duclos et al 1993, Thomas-Delloye et al 1999, Dupont et al 2009). Dans la partie de génome séquencée du poulet, aucune séquence ne semble coder un transporteur de glucose insulino-sensible GLUT-4. Il faut cependant garder à l'esprit que tout le génome de poulet n'est pas séquencé à ce jour. Des mesures de transport de 2-deoxyglucose suite à une injection d'insuline chez le poulet in vivo suggèrent cependant fortement l'existence d'un transporteur de glucose insulino-dépendant (Tokushima et al 2005). De plus, l'existence d'une isoforme fonctionnelle proche de GLUT-4 a été suggérée chez le canard (Thomas-Delloye et al 1999). Le fait de ne pas pouvoir identifier de GLUT-4 chez les Oiseaux peut résulter d'un manque d'activité hétérospécifique des anticorps dirigés contre les GLUT-4s de Mammifères.

Les isoformes HKI et HKII sont exprimées dans le muscle squelettique du poulet. Leur expression augmente significativement après un jeûne de $48 \mathrm{~h}$ ou après $24 \mathrm{~h}$ de réalimentation contrairement aux Mammifères (Seki et al 2005).

\section{2 / Stockage du glucose sous forme de glycogène ou de lipides}

Lorsque la glycémie est élevée, le glucose non utilisé pour la production d'énergie est mis en réserve sous forme de glycogène par la voie de la glycogénogenèse dans le foie essentiellement et dans le muscle. Lorsque la capacité maximale de synthèse hépatique de glycogène est atteinte, le glucose en excès 
est mis en réserve sous forme de lipides par la voie de la lipogenèse et stocké dans le foie et le tissu adipeux.

\section{a) Dans le foie}

Glycogénogenèse. L'état nutritionnel modifie très fortement l'expression des gènes du métabolisme hépatique. La privation de nourriture s'accompagne d'une diminution importante du glycogène hépatique chez des poulets de chair de 6 semaines $(-77 \%$ après $24 \mathrm{~h}$ de jeûne) qui compensent par une «surconsommation» après réalimentation $(+380 \% 12 \mathrm{~h}$ après réalimentation $)$ (Edwards et al 1999). Cette surcompensation est connue chez les Mammifères (Nur et al 1995). Une étude récente montre que par rapport à des poulettes reproductrices alimentées tous les jours, des poulettes alimentées 1 jour sur 2 à partir de 4 semaines d'âge dans le but de diminuer la consommation alimentaire, présentent à 16 semaines d'âge de très fortes modifications du poids du foie et de son contenu en glycogène et en lipides sans modification de la consommation totale (de Beer et al 2007). Cette restriction alimentaire suivie d'une réalimentation ressemble à ce qui est observé chez des poulets en croissance soumis à un jeûne puis réalimentés; elle conduit cependant à long terme, à une accumulation excessive de lipides dans le foie, à un risque potentiel de syndrome de foie gras hémorragique et à la mort, même si on revient à une alimentation quotidienne en fin d'élevage (Ekmay et al 2010). Le glycogène musculaire (muscle pectoral) est en revanche peu influencé par les changements métaboliques induits par le jeûne et la réalimentation (Edwards et al 1999). Il diminue de $13 \%$ après $24 \mathrm{~h}$ de jeûne et ne présente aucune variation par rapport aux témoins $12 \mathrm{~h}$ après réalimentation. La régulation différentielle entre le foie et le muscle pourrait résulter d'une expression du récepteur du glucagon plus faible dans le muscle que dans le foie (Edwards et al 1999), comme chez le rat (Hansen et al 1995). Les variations d'origine génétique et liées à la nature des régimes ainsi que les mécanismes moléculaires pour la synthèse de glycogène sont décrits plus loin pour le muscle.

Lipogenèse. Le foie est un organe essentiel pour la synthèse des lipides chez les Oiseaux. Le tissu adipeux présente en effet une très faible capacité de biosynthèse de triglycérides de novo (Saadoun et Leclercq 1983, 1986) contrairement à d'autres espèces telles que le porc et les ruminants, où la majeure partie des Acides Gras (AG) est synthétisée par le tissu adipeux (Hanson et Ballard 1967, Mourot et Kouba 1999). La différence de capacité lipogé- nique des deux tissus est liée à une expression importante du gène SREBP1 dans le foie des poulets et beaucoup plus faible dans le tissu adipeux (Gondret et al 2001). Chez le canard, Chartrin et al (2006) ont rapporté que l'activité des enzymes de la lipogenèse est 100 fois plus faible dans le muscle Pectoralis major que dans le foie et 10 fois plus faible dans le tissu adipeux.

L'état nutritionnel des poulets influence fortement la lipogenèse hépatique en agissant non seulement sur l'activité des enzymes mais encore sur l'expression des gènes. La restriction alimentaire diminue très significativement l'expression des gènes d'enzymes clé de la lipogenèse hépatique des poulets de chair (Goodridge 1987, Richards et al 2003, Desvergne et al 2006, de Beer et al 2007). A l'opposé, le glucose apporté de façon massive sous forme d'amidon est converti dans le foie en $A G$, puis en triglycérides et lipoprotéines. Dans certaines espèces de palmipèdes telles que le canard de barbarie (Cairina moschata) et l'oie des Landes (Anser anser), l'intensité de synthèse des lipides par le foie dépasse les possibilités de sécrétion de telle sorte que les lipides néo-synthétisés s'accumulent progressivement, conduisant à la formation de foie gras en moins de deux semaines de gavage. L'importance de la stéatose hépatique est influencée par la nature des sucres. Un aliment de gavage enrichi en fructose produit chez le canard mulard, un foie gras significativement plus lourd (environ de 20\%) qu'un aliment apportant du glucose en quantités comparables (Davail et al 2005). La lipogenèse in vitro est par ailleurs inversement liée au taux protéique du régime (variant de 12 à 30\%); la diminution de l'expression des gènes de la lipogenèse (enzyme malique mais aussi acide gras synthase et acétyl-CoA carboxylase) n'a toutefois lieu que lorsque l'aliment contient de très hauts niveaux de protéines (30\%) (Rosebrough et al 2008).

L'origine génétique des animaux joue un rôle important dans la lipogenèse hépatique. Deux lignées de poulets maigres ou gras (lignées «Maigre et Grasse») sélectionnées de façon divergente sur le pourcentage de gras abdominal, constituent un matériel de choix pour identifier des mécanismes impliqués dans l'engraissement. Les animaux issus de la lignée Grasse présentent un engraissement abdominal environ trois fois supérieur à celui des animaux de la lignée Maigre alors que leurs poids vifs diffèrent peu (Simon et Leclercq 1982). La lignée Grasse se caractérise par une glycémie plus faible que celle de la lignée Maigre (Touchburn et al 1981), ce qui suggère une utilisation du glucose par les tissus périphériques plus impor- tante chez les poulets Gras. L'ensemble des données obtenues sur ces lignées montre effectivement que les poulets de la lignée Grasse ont un métabolisme qui favorise le stockage du glucose, que ce soit sous forme lipidique dans le foie et les tissus adipeux ou de glycogène dans le muscle. La différence d'engraissement entre les deux lignées provient principalement du métabolisme hépatique des $\mathrm{AG}$, plus actif dans la lignée Grasse que dans la lignée Maigre (Douaire et al 1992, Legrand et Hermier 1992, Daval et al 2000, Assaf et al 2004, Bourneuf et al 2006). A l'origine de l'engraissement accru de la lignée Grasse, on note une différence dans l'équilibre glycémie-insulinémie des deux lignées (Touchburn et al 1981, Saadoun et al 1988), un dysfonctionnement dans la cinétique de la sécrétion d'insuline en réponse au glucose (Rideau et al 1986) et une activation significativement plus importante des étapes précoces de la signalisation de l'insuline dans le foie des poulets de la lignée Grasse (Dupont et al 1999), qui favoriseraient la lipogenèse hépatique et par conséquent le dépôt de graisse abdominale dans le génotype Gras. L'influence du génotype sur la lipogenèse hépatique a aussi été étudiée chez le canard (Baeza et al 2005). Les différentes espèces de canards ne sont en effet pas toutes aptes à produire un foie gras, le canard Commun (ou canard Pékin, Anas platyrhynchos) présentant une aptitude à la stéatose hépatique plus faible que celle du canard de Barbarie (Cairina moschata). L'activité des enzymes (Baeza et al 2005 ) et l'expression des gènes impliquées dans la lipogenèse hépatique (Herault et al 2010) est supérieure chez le canard de Barbarie, ce qui pourrait expliquer, en partie, sa meilleure aptitude à la production de foie gras. Le canard Pékin semblerait néanmoins plus apte à limiter la stéatose hépatique en sécrétant des VLDL plus riches en triglycérides. Ce mécanisme, associé à un captage musculaire de lipides circulants plus intense, une capacité de stockage intramusculaire des lipides supérieure et une lipogenèse musculaire supérieure par rapport au canard de Barbarie, permettrait d'expliquer l'engraissement intramusculaire plus important du canard Pékin (Saez et al 2009).

Comme chez les Mammifères, l'insuline et la triiodothyronine stimulent la biosynthèse des $\mathrm{AG}$ en agissant sur la transcription des gènes de la lipogenèse tandis que le glucagon et les glucocorticoïdes exercent des effets anti-lipolytiques. A moyen et long terme, les effets de l'insuline sont relayés par le SREBP-1 qui joue comme chez les Mammifères (Horton et al 2002) un rôle de médiateur majeur intégrant les actions de l'insuline, de la T3, du 
Figure 4. Régulation du transport de glucose dans le muscle et synthèse de glycogène.

AMPK : adenosine monophosphate-activated proteine kinase ; Akt/PKB : protéine kinase B ; GSK3 : glycogène synthase kinase 3 ; PHK : phosphorylase kinase ; PYG : glycogène phosphorylase ; GYS : glycogène synthase.

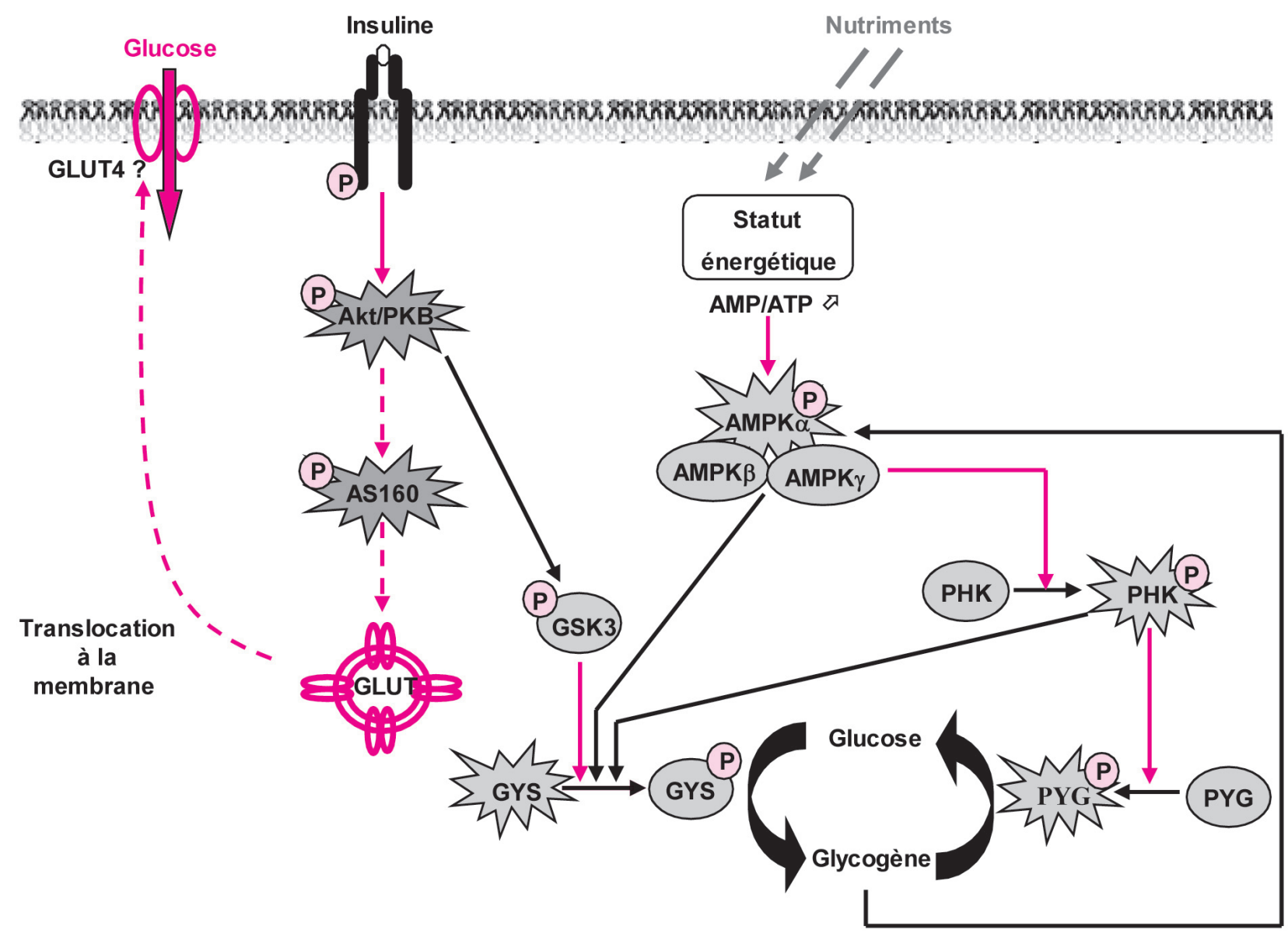

La glycogène synthase (GYS) est l'enzyme principale et limitante de la synthèse de glycogène dans tous les organes. La glycogène synthétase kinase 3 (GSK3) régule le métabolisme du glycogène en phosphorylant la GYS. A l'opposé, la glycogène phosphorylase (PYG) est l'enzyme clé de la glycogénolyse. La PYG du foie est sensible aux variations de glucose ; son activité est contrôlée par la phosphorylation plus que par régulation allostérique. La forme musculaire de la PYG en revanche est activée en présence de concentrations élevées d'AMP, qui agit de façon allostérique en se liant au site de liaison du nucléotide altérant ainsi sa conformation et l'activité de l'enzyme. La glycogène phosphorylase kinase (PHK) catalyse la phosphorylation et l'activation de la PYG.

glucagon et des glucocorticoïdes sur la transcription des gènes de la lipogenèse lors du jeûne et de la réalimentation (Zhang et al 2003) ou lors d'un stress (Cai et al 2011). La présence d'une seule isoforme de SREBP-1 suggère que la lipogenèse hépatique présente des particularités chez les Oiseaux comparés aux Mammifères (Zhang et al 2003). Des travaux complémentaires s'avèrent encore nécessaires pour mieux cerner le rôle de la ChREBP («Carbohydrate Response Element-Binding Protein») dans la régulation de la lipogenèse hépatique à partir du glucose chez les Oiseaux (Proszkowiec-Weglarz et al 2009).

\section{b) Dans le muscle}

Régulation du stockage musculaire $d u$ glucose sous forme de glycogène. Les voies de la synthèse de glycogène et de sa régulation sont présentées dans la figure 4 . Des analyses combinées de génomique fonctionnelle et positionnelle ont permis d'appréhender les mécanismes physiologiques impliqués dans les variations du glycogène musculaire. Les analyses du transcriptome réalisées avec des puces à $\mathrm{ADN}$ suggèrent que des régulations au niveau transcriptionnel d'un certain nombre de gènes peuvent intervenir dans le contrôle des réserves musculaires en glycogène (Sibut et al 2011). Les analyses par PCR quantitative d'expression ciblées sur des gènes connus pour leur rôle dans la régulation de métabolisme du glycogène ( protein kinase» (AMPK), glycogène synthase (GS), glycogène phosphorylase (PYG), glycogène phosphorylase kinase (PHK)...) dans d'autres espèces confirment par ailleurs leur implication dans le contrôle des caractères de qualité de viande chez le poulet (Sibut et al 2008).
Des études complémentaires de signalisation ont démontré le rôle central de l'activation par phosphorylation de l'AMPK dans le contrôle des réserves en glycogène musculaire, qu'elles soient modulées par la génétique (Sibut et al 2008) ou la nutrition (Mameri et al 2010, Jlali et al 2012).

Variations d'origine génétique. L'expression et/ou l'activité de kinases importantes pour le métabolisme glucidique ont été comparées chez des poulets sélectionnés de façon divergente sur le gras abdominal (lignées Maigre et Grasse ; Leclercq et al 1988). Ces animaux présentent des différences de concentration en glucose plasmatique (Gras < Maigre) (Touchburn et al 1981) et de teneur en glycogène du muscle Pectoralis major (Gras > Maigre) (Sibut et al 2008). Des différences de niveaux d'expression mais aussi de 
phosphorylation d'enzymes impliqués dans la synthèse ou la dégradation du glycogène ont pu être montrées entre les deux lignées. $\mathrm{Au}$ niveau transcriptionnel, des différences d'expression ont pu être mises en évidence pour plusieurs sous-unités de l'AMPK ainsi que de plus fortes expressions de la glycogène synthase, de la glycogène phosphorylase et de la sous-unité $\gamma$ de la phosphorylase kinase dans la lignée Maigre. De plus, le niveau de phosphorylation de la sous-unité $\alpha$ de l'AMPK sur Thr172 s'est avéré 3 fois plus élevé dans le muscle d'animaux de la lignée Maigre par rapport à celui d'animaux de la lignée Grasse (Sibut et al 2008). La plus forte activation de l'AMPK observée dans la lignée Maigre est en accord avec la diminution du contenu en glycogène du muscle. L'activation de l'AMPK est connue pour diminuer le stockage de glucose en glycogène par activation de la glycogène phosphorylase et inhibition de la glycogène synthase (Carling et Hardie 1989, Longnus et al 2003, Jørgensen et al 2004, Miyamoto et al 2007). L'ensemble de ces observations suggère une meilleure captation du glucose par la cellule musculaire conduisant à un contenu en glycogène plus élevé dans la lignée Grasse.

Variations d'origine nutritionnelle. D'autres études ont montré que la teneur en protéines brutes du régime peut aussi affecter la qualité technologique de la viande en modulant les réserves en glycogène du muscle et ce différemment en fonction des génotypes étudiés (Jlali et al 2012). Les mécanismes sous-jacents sont encore mal connus, mais la nutrition semble être un bon moyen pour modifier les teneurs en glycogène du muscle chez l'oiseau et par conséquent la qualité de leur viande puisque chez le poulet les réserves musculaires en glycogène disponibles au moment de la mort, ou potentiel glycolytique, constituent un élément déterminant de la qualité technologique via leurs effets sur le $\mathrm{pH}$ ultime de la viande (Le Bihan-Duval et al 2008a). Quelques données de la littérature décrivent les rôles potentiels des acides aminés dans la régulation du métabolisme glucidique (Tremblay et al 2007, Deshmukh et al 2009, Tesseraud et al 2009). Chez le poulet, le rôle de signal des acides aminés a été principalement étudié avec la leucine (acide aminé à chaîne ramifiée) qui est capable d'initier des voies de transduction intracellulaires et de stimuler l'initiation de la traduction protéique. Des études comparables avec d'autres acides aminés sont rares (Métayer et al 2008, Tesseraud et al 2009). Une étude récente a montré que des régimes enrichis en lysine modifiaient la teneur en glycogène du muscle et donc pouvaient améliorer la qualité du muscle pectoral

Encadré 4. La protéine kinase AMP dépendante (AMPK), un senseur du niveau énergétique intracellulaire qui participe à la régulation de la glycémie (état des connaissances chez les Mammifères).

1- La protéine kinase AMP dépendante est exprimée dans de nombreux tissus de l'organisme. Elle est activée par une élévation du taux d'AMP. Cette relation entre concentration en AMP et activité enzymatique lui permet de jouer le rôle de senseur du niveau énergétique cellulaire.

2- Dans le muscle, l'exercice musculaire active l'AMPK qui, en phosphorylant d'autres enzymes clés du métabolisme, induit une translocation des transporteurs GLUT4 et donc le transport de glucose, puis stimule l'entrée des acides gras dans la mitochondrie et leur oxydation.

3- Dans le foie, une activation de l'AMPK conduit à une diminution de la production de glucose. Dans le foie, l'AMPK régule négativement les voies consommatrices d'ATP comme la néoglucogenèse, la lipogenèse, la synthèse des triglycérides ou encore celle du cholestérol ; elle régule positivement les voies générant de l'ATP comme l'oxydation des lipides.

4- Outre le niveau énergétique cellulaire, l'AMPK est activée par l'adiponectine, une adipocytokine dont la concentration est fortement associée à la sensibilité à l'insuline. Chez I'homme obèse insulinorésistant, les concentrations d'adiponectine sont abaissées, l'activité de l'AMPK est basse et on observe une résistance à l'insuline. La metformine est une substance pharmacologique utilisée depuis plusieurs décennies dans le traitement du diabète de type 2 , qui s'avère être un activateur de l'AMPK.

5- L'AMPK est aussi exprimée au niveau de l'hypothalamus et contribue aux régulations centrales du métabolisme (Daval 2006, Hardie 2011).

en augmentant son $\mathrm{pH}$ ultime et sa capacité de rétention en eau (Berri et al 2008). Une meilleure connaissance des mécanismes par lesquels les acides aminés régulent le métabolisme, la signalisation intracellulaire, l'expression de gènes et les fonctions cellulaires seront nécessaires avant de proposer des alternatives nutritionnelles pour améliorer le contrôle de l'utilisation des nutriments et optimiser les complémentations des régimes alimentaires en acides aminés. De nouveaux protocoles alimentaires pourront alors laisser envisager des stratégies nutritionnelles visant à diminuer le coût d'élevage des animaux, et des applications pour améliorer la qualité de la viande et/ou sa transformation technologique. Ces protocoles visent à faire évoluer différents systèmes de production répondant à des attentes variées (économiques, sociales, de consommation) pour améliorer leur durabilité.

\section{c) Dans le tissu adipeux}

Chez les Mammifères, le tissu adipeux joue un rôle crucial dans le contrôle de l'homéostasie énergétique du corps. Ce contrôle est fréquemment perturbé chez l'Homme conduisant au développement de l'obésité et du diabète. Un nombre croissant de protéines sécrétées par les tissus adipeux signale l'état des stocks énergétiques corporels au cerveau et aux tissus périphériques et module ainsi plusieurs fonctions physiologiques comme le métabolisme du glucose et la sensibilité des tissus à l'insuline. Comme chez les Mammifères, le poulet est aussi sujet à l'engraissement. Probablement comme effet secondaire résultant de l'intense sélection sur les niveaux de croissance corporelle, le gras excessif est devenu un problème majeur pour l'industrie du poulet. Cela diminue le rendement de carcasse et l'efficacité alimentaire, génère du travail supplémentaire et détériore l'acceptabilité du produit par les consommateurs. Chez l'oiseau, la lipogenèse ayant lieu essentiellement dans le foie, les mécanismes potentiellement impliqués dans la régulation de l'adiposité chez le poulet ont été étudiés principalement sur le tissu hépatique. L'activité lipogénique du tissu adipeux est faible, son activité lipolytique est presque exclusivement glucagon-dépendante et le rôle de l'insuline y est peu clair. En effet, les études de signalisation de l'insuline, nombreuses dans le foie et le muscle, sont quasiment inexistantes dans le tissu adipeux. Jusque là, la présence de récepteurs à insuline dans les adipocytes de poulet a seulement été montrée via des mesures de liaison de l'insuline à des membranes d'adipocytes (Bassas et al 1988). Des mesures indirectes avec de fortes doses d'insuline suggèrent que l'insuline stimule le transport de glucose dans les adipocytes de poulet (Langslow et Hales 1969) via un transporteur encore non identifié puisque comme dans le muscle, le transporteur de glucose GLUT-4 n'est pas exprimé dans le tissu adipeux aviaire. En revanche, GLUT-1 et -3 y sont exprimés (Duclos et al 1993, Kono et al 2005). Les éléments de la cascade de signalisation insulinique ont été caractérisés dans le tissu adipeux de poulet et leur régulation a été évaluée en réponse à des statuts nutritionnels différents (nourri vs à jeun) ou suite à une immuno-neutralisation de l'insuline in vivo (Dupont et al 2012). Ces études ont montré que les récepteurs à insuline ainsi que tous les 
éléments régulant la cascade insulinique étaient bien présents dans le tissu adipeux aviaire. Cependant, aucune régulation n'a pu être mise en évidence en réponse aux stimuli (à jeun, nourri, privation d'insuline), mettant en évidence une apparente résistance du tissu adipeux à l'insuline. La signalisation de l'insuline dans le tissu adipeux de poulet est donc également très différente de celle décrite chez les Mammifères.

\section{Conclusion}

En dépit de nombreux travaux réalisés au cours de ces 40 dernières années sur le métabolisme glucidique des Oiseaux et des développements chez le poulet et le canard rapportés dans cette synthèse, il reste encore de nombreuses interrogations (Scanes 2009). Les bases biologiques permettant d'expliquer pourquoi les Oiseaux domestiques (et sauvages) présentent une glycémie basale aussi élevée (avec des niveaux plasmatiques d'insuline semblables aux Mammifères, Simon et al 2011), sans que par ailleurs cela ne perturbe le fonctionnement des tissus contrairement aux autres espèces non aviaires, ne sont pas encore connues (Braun et Sweazea 2008, Scanes 2009).

Chez les Oiseaux comme dans la plupart des espèces non aviaires, la glycémie varie dans des limites étroites et ne s'en écarte fortement que dans certaines situations pathologiques rares telle que le syndrome "hypoglycemia-spiking mortality», où des poulets malades présentent une hypoglycémie majeure (pouvant aller jusqu'à $0,17 \mathrm{~g} / \mathrm{L}$ chez des Oiseaux à jeun ou anorexiques). Une altération de la production de glucagon a été suggérée mais non validée jusqu'à présent (Davis et Vasilatos-Younken 1995). Il est toutefois possible de moduler la glycémie lors de manipulations expérimentales. La privation d'insuline par pancréatectomie ou immunoneutralisation induit une hyperglycémie marquée. A l'opposé, une hypoglycémie notable résulte de l'administration aiguë d'insuline à fortes doses ou celle d'agents pharmacologiques spécifiques tels que le tolbutamide, un activateur de glucokinase ou encore le troglitazone (agoniste PPAR, Fukao et al 2006). Globalement, ces différents agents exercent un effet hypoglycémiant semblable à celui observé chez les Mammifères, ce qui suggère que le poulet est équipé de systèmes qualitativement analogues aux Mammifères. Il existe cependant des différences liées au fonctionnement particulier mais encore inexpliqué des tissus aviaires tel que l'insensibilité des muscles ou du tissu adipeux à l'action de l'insuline, ou l'insensibilité de la cellule $\beta$-pancréatique aux nutriments énergétiques. Des travaux complémen- taires concernant les voies de signalisation dans les tissus glucosensibles et insulinosensibles s'avèrent nécessaires.

Des perturbations plus modestes de la glycémie (et de la relation glucose-insuline), mais non sans conséquence sur le métabolisme, la croissance des tissus et la composition corporelle des poulets sont rapportés dans différents modèles génétiques expérimentaux : lignées de poulets Maigre ou Grasse qui présentent par ailleurs un poids corporel semblable, lignées présentant une glycémie basale (à jeun) basse ou élevée, lignées à croissance lente ou rapide, lignées normales vs naines (Leclercq et al 1987 , Leclercq et al 1988, Gueritault et al 1990, Beccavin et al 2001). On observe également des changements de la relation glucose-insuline et de la composition corporelle dans des croisements commerciaux de poulet de chair après traitement chronique par de la corticostérone exogène (Taouis et al 1993), chez des poulets soumis à un stress thermique (Boussaid-Om Ezzine et al 2010) ou nourris de façon intermittente (Simon et Rosselin 1979). Contrairement à ce qui est généralement observé chez les Mammifères, l'engraissement est associé à une glycémie plus faible chez le poulet (voir les références citées dans Nadaf et al 2009) ou le canard (Chartrin et al 2006). Un lien étroit entre la glycémie et l'adiposité a été confirmé récemment dans une recherche de QTL pour des caractères métaboliques et de composition corporelle : plusieurs QTL métaboliques ont été identifiés pour la glycémie et la température corporelle qui par ailleurs étaient colocalisés avec des QTL pour le poids des poulets ou le gras abdominal (Nadaf et al 2009). L'identification des gènes impliqués dans les QTL de glycémie devrait contribuer à améliorer la compréhension de la glycémie élevée constitutive du poulet et des autres espèces aviaires.

Les particularités du métabolisme glucidique des Oiseaux ont-elles conduit à une glycémie élevée ou au contraire la glycémie élevée a-t-elle engendré des processus adaptatifs particuliers ? La réponse est loin d'être connue. Toutefois, les Oiseaux constituent un modèle original pour étudier non seulement les perturbations de la glycémie rencontrées en pathologie humaine lors du diabète ou de l'obésité, mais de façon plus générale pour explorer d'un point de vue comparatif la physiologie du glucose. Certains champs restent encore imprécis tels que le fonctionnement du facteur de transcription ChREBP comme intermédiaire du glucose dans l'expression des gènes de la glycolyse et de la lipogenèse mis en évidence chez les mammifères (Denechaud et al 2008), le rôle du glucose dans la régu- lation centrale de l'appétit et dans la régulation de la dépense énergétique, les relations entre l'hyperglycémie et le stress oxydatif chez les Oiseaux c'est à dire les mécanismes de défense contre l'hyperglycémie propres aux Oiseaux (Klandorf et al 1999, Braun et Sweazea 2008), etc. Par ailleurs, de nouveaux domaines sont encore totalement vierges chez les Oiseaux. Citons la régulation des protéines par O-linked N-acétylglucosamylation (O-GlcNAc) induite par le glucose via la voie de la glucosamine (Issad et Kuo 2008), la production glycolytique de NAD+ et son rôle sur l'activité de la Sirt1-deacetylase, qui s'avère être un régulateur important de la transcription des gènes ( $\mathrm{Yu}$ et Auwerx 2009), la modification d'histones par l'acétyl-CoA produit au cours du métabolisme du glucose et les modifications du contrôle épigénétique de l'expression des gènes qui en résultent (Wellen et al 2009, Thorens et Mueckler 2010). Le poulet et les Oiseaux en général, du fait de leur glycémie basale intrinsèquement élevée et des spécificités qui en découlent, constituent un élément incontournable du puzzle. Les spécificités aviaires concernent aussi vraisemblablement un phylum particulier de la classe des reptiles : les lézards qui appartiennent à la même branche évolutive que les Oiseaux et qui présentent des analogies de la régulation glycémique, notamment une glycémie élevée (Epple et Brinn 1987).

D'un point de vue pratique pour le poulet de chair, la compréhension des mécanismes contrôlant la croissance musculaire et la composition corporelle est une question centrale puisque ces critères ont des répercussions sur l'efficacité des productions, la quantité de rejets, la qualité nutritionnelle et/ou technologique des produits, les performances de reproduction et la santé. Comprendre les mécanismes contrôlant l'engraissement, la croissance musculaire et la qualité des viandes revient en partie à comprendre les mécanismes qui régulent l'utilisation périphérique du glucose (et par là même la glycémie). En effet, 1'apport d'énergie sous forme de glucose, son transport et son utilisation par le foie, les muscles ou le tissu adipeux sont des processus essentiels, qui conditionnent la lipogenèse, la protéosynthèse et la glycogénogenèse et par là même la croissance protéique musculaire et la qualité des produits. Rappelons par exemple que l'anabolisme du muscle Pectoralis major (glycolytique) dépend très fortement de la fourniture en glucose. Nous avons montré par ailleurs que les propriétés technologiques et sensorielles de la viande sont influencées par les réserves du muscle en glycogène au moment de la mort. L'identification des mécanismes 
physiologiques à l'origine des variations de qualité de la viande chez le poulet doit à terme permettre de déve- lopper des outils moléculaires utiles pour la sélection, mais aussi pour optimiser les pratiques d'élevage (en parti- culier l'alimentation) en vue d'améliorer la qualité des viandes (Le BihanDuval et al 2008b).

\section{Références}

Agius L., 2008. Glucokinase and molecular aspects of liver glycogen metabolism. Biochem. J., 414, 1-18.

Akiba Y., Chida Y, Takahashi T., Ohtomo Y., Sato K., Takahashi K., 1999. Persistent hypoglycemia induced by continuous insulin infusion in broiler chickens. Br. Poult. Sci., 40, 701-705.

Assaf S., Lagarrigue S., Daval S., Sansom M., Leclercq B., Michel J., Pitel F., Alizadeh M., Vignal A., Douaire M., 2004. Genetic linkage and expression analysis of SREBP and lipogenic genes in fat and lean chicken. Comp. Biochem. Physiol. B Biochem. Mol. Biol., 137, 433-441.

Baeza E., Rideau N., Chartrin P., Davail S., Hoo-Paris R., Mourot J., Guy G., Bernardet M.D., Juin H., Meteau K., Hermier D., 2005. Canards de Barbarie, Pékin et leurs hybrides : aptitude à l'engraissement. INRA Prod. Anim., $18,131-141$.

Bassas L., Lesniak M.A., Serrano J., Roth J., de Pablo F., 1988. Developmental regulation of insulin and type I insulin-like growth factor receptors and absence of type II receptors in chicken embryo tissues. Diabetes, 37 , 637-644.

Beccavin C., Chevalier B., Cogburn L.A., Simon J., Duclos M.J., 2001. Insulin-like growth factors and body growth in chickens divergently selected for high or low growth rate. J. Endocrinol., 168, 297-306.

Belo P.S., Romsos D.R., Leville G.A., 1976. Blood metabolites and glucose metabolism in the fed and fasted chicken. J. Nutr., 106, 11351143.

Berradi H., Guy G., Rideau N., 2004. A glucokinase-like enzyme induced in Mule duck livers by overfeeding. Poult. Sci., 83, 161-168.

Berradi H., Taouis M. Cassy S, Rideau N. 2005. Glucokinase in chicken (Gallus gallus). Partial cDNA cloning, immunodetection and activity determination. Comp. Biochem. Physiol. B Biochem. Mol. Biol., 141, 129-139.

Berri C., Besnard J., Relandeau C., 2008. Increasing dietary lysine increases final $\mathrm{pH}$ and decreases drip loss of broiler breast meat. Poult. Sci., 87,480-484.

Bourneuf E., Herault F., Chicault C., Carre W., Assaf S., Monnier A., Mottier S., Lagarrigue S., Douaire M., Mosser J., Diot C., 2006. Microarray analysis of differential gene expression in the liver of lean and fat chickens. Gene, 372, 162-170.

Boussaid-Om Ezzine S., Everaert N., Métayer-Coustard S., Rideau N., Berri C., Joubert R., Temim S., Collin A., Tesseraud S., 2010 Effects of heat exposure on Akt/S6K1 signaling and expression of genes related to protein and energy metabolism in chicken (Gallus gallus) pectoralis major muscle. Comp. Biochem. Physiol. B Biochem. Mol. Biol., 157, 281-287.

Braun E.J., Sweazea K.L., 2008. Glucose regulation in birds. Comp. Biochem. Physiol. B Biochem. Mol. Biol., 151, 1-9.
Buyse J., Janssens K., Van der Geyten S., Van As P., Decuypere E., Darras V.M., 2002. Pre- and post-prandial changes in plasma hormone and metabolite levels and hepatic deiodinase activities in meal-fed broiler chickens. Br. J. Nutr., 88, 641-653.

Buyse J., Geypens B., Malheiros R.D., Moraes V.M., Swennen Q., Decuypere E., 2004. Assessment of age-related glucose oxidation rates of broiler chickens by using stable isotopes. Life Sci., 75, 2245-2255.

Cai Y., Song Z., Wang X., Jiao H., Lin H., 2011. Dexamethasone-induced hepatic lipogenesis is insulin dependent in chickens (Gallus gallus domesticus). Stress, 14, 273-281.

Cardenas M.L., Cornish-Bowden A., Ureta T., 1998. Evolution and regulatory role of the hexokinases. Biochim. Biophys. Acta, 1401, 242-264.

Carling D., Hardie D.G., 1989. The substrate and sequence specificity of the AMP-activated protein kinase. Phosphorylation of glycogen synthase and phosphorylase kinase. Biochim. Biophys. Acta, 1012, 81-86.

Carver F.M., Shibley I.A. Jr., Pennington J.S., Pennington S.N., 2001. Differential expression of glucose transporters during chick embryogenesis. Cell. Mol. Life Sci., 58, 645652 .

Chartrin P., Bernadet M.D., Guy G., Mourot J., Hocquette J.F., Rideau N., Duclos M.J., Baeza E., 2006. Does overfeeding enhance genotype effects on liver ability for lipogenesis and lipid secretion in ducks? Comp. Biochem. Physiol. A Mol. Integr. Physiol., 145, 390-396.

Datar S.P., Bhonde R.R., 2006. A simple technique for isolation of functional $\mathrm{B}$ islets from chick pancreas. J. Cell. Tissue Res., 6, 605-608.

Davail S., Rideau N., Bernadet M.D., André J.M., Guy G., Hoo-Paris R., 2005. Effects of dietary fructose on liver steatosis in overfed mule ducks. Horm. Metab. Res., 37, 32-35.

Daval S., Lagarrigue S., Douaire M., 2000 Messenger RNA levels and transcription rates of hepatic lipogenesis genes in genetically lean and fat chickens. Genet. Sel Evol., 32, 521531 .

Daval M., Ferré P., Foufelle F., 2006 L'AMPK : une enzyme au coeur de l'homéostasie énergétique. J. Soc. Biol., 200, 99-105.

Davis J.F., Vasilatos-Younken R., 1995. Markedly reduced pancreatic glucagon levels in broiler chickens with spiking mortality syndrome. Avian Dis., 39, 417-419.

de Beer M., Rosebrough R.W., Russell B.A., Poch S.M., Richards M.P., Coon C.N., 2007. An examination of the role of feeding regimens in regulating metabolism during the broiler breeder grower period. 1. Hepatic lipid metabolism. Poult. Sci., 86, 1726-1738.

de Oliveira J.E., Uni Z., Ferket P.R., 2008. Important metabolic pathways in poultry embryos prior to hatch. World's. Poult. Sci. J., 64, 488-499.
Denechaud P.D., Dentin R., Girard J., Postic C., 2008. Role of ChREBP in hepatic steatosis and insulin resistance. FEBS Lett., 582, 68-73.

Deshmukh A., Salehzadeh F., MétayerCoustard S., Fahlman R., Nair K.S., Al-Khalili L., 2009. Post-transcriptional gene silencing of ribosomal protein S6 kinase 1 restores insulin action in leucine-treated skeletal muscle. Cell. Mol. Life Sci., 66, 1457-1466.

Desvergne B., Michalik L., Wahli W., 2006. Transcriptional regulation of metabolism. Physiol. Rev., 86, 465-514.

Douaire M., Le Fur N., el Khadir-Mounier C., Langlois P., Flamant F., Mallard J., 1992. Identifying genes involved in the variability of genetic fatness in the growing chicken. Poult. Sci., 71, 1911-1920.

Duclos M.J., Chevalier B., Le MarchandBrustel Y., Tanti J.F., Goddard C., Simon J., 1993. Insulin-like growth factor-I-stimulated glucose transport in myotubes derived from chicken muscle satellite cells. J. Endocrinol., 137, 465-472.

Dupont J., Chen J., Derouet M., Simon J., Leclercq B., Taouis M., 1999. Metabolic differences between genetically lean and fat chickens are partly attributed to the alteration of insulin signaling in liver. J. Nutr., 129, 1937-1944.

Dupont J., Tesseraud S., Derouet M., Collin A., Rideau N., Crochet S., Godet E., CailleauAudouin E., Metayer-Coustard S., Duclos M.J., Gespach C., Porter T.E., Cogburn L.A., Simon J., 2008. Insulin immuno-neutralization in chicken: effects on insulin signaling and gene expression in liver and muscle. J. Endocrinol., 197, 531-542.

Dupont J., Tesseraud S., Simon J., 2009. Insulin signaling in chicken liver and muscle. Gen. Comp. Endocrinol., 163, 52-57.

Dupont J., Métayer-Coustard S., Ji B., Ramé C., Gespach C., Voy B., Simon J., 2012. Characterization of major elements of insulin signaling cascade in chicken adipose tissue: Apparent insulin refractoriness. Gen. Comp. Endocrinol., 176, 86-93.

Edwards M.R., McMurtry J.P., VasilatosYounken R., 1999. Relative insensitivity of avian skeletal muscle glycogen to nutritive status. Domest. Anim. Endocrinol., 16, 239247.

Epple A., Brinn J.E., 1987. The Comparative Physiology of the Pancreatic Islets. Springer-Verlag, Berlin, New York, 223p.

Ekmay R.D., de Beer M., Rosebrough R.W., Richards M.P., McMurtry J.P., Coon C.N., 2010. The role of feeding regimens in regulating metabolism of sexually mature broiler breeders. Poult. Sci., 89, 1171-1181.

Farhat A., Chavez E.R., 2000. Comparative performance, blood chemistry, and carcass composition of two lines of Pekin ducks reared mixed or separated by sex. Poult. Sci., 79, 460465.

Fukao K., Akiba Y., Nishiki Y., Tokushima Y., Kono T., Sato K., 2006. Improvement in 
glucose tolerance and skeletal muscle glucose transport in broiler chickens treated with PPARgamma agonist Troglitazone. World's. Poult. Sci. J., XII Europ. Poultry Conf., Verona, Italy.

Girard J., Ferre P., Foufelle F., 1997. Mechanisms by which carbohydrates regulate expression of genes for glycolytic and lipogenic enzymes. Annu. Rev. Nutr., 17, 325-52.

Gondret F., Ferre P., Dugail I., 2001. ADD1/SREBP-1 is a major determinant of tissue differential lipogenic capacity in mammalian and avian species. J. Lipid. Res., 42, 106-113.

Goodridge A.G., 1987. Dietary regulation of gene expression: enzymes involved in carbohydrate and lipid metabolism. Ann. Rev. Nutr., 7, 157-85.

Griffin H.D., Guo K., Windsor D., Butterwith S.C., 1992. Adipose tissue lipogenesis and fat deposition in leaner broiler chickens. J. Nutr., 122, 363-368.

Grimsby J., Sarabu R., Corbett W.L., Haynes N.E., Bizzarro F.T., Coffey J.W., Guertin K.R., Hilliard D.W., Kester R.F., Mahaney P.E., Marcus L., Qi L., Spence C.L., Tengi J., Magnuson M.A., Chu C.A., Dvorozniak M.T., Matschinsky F.M., Grippo J.F., 2003. Allosteric activators of glucokinase: potential role in diabetes therapy. Science, 301 , 370-373

Gueritault I., Simon J., Chevalier B., Derouet M., Tixier-Boichard M., Merat P., 1990. Increased in-vivo insulin sensitivity but normal liver insulin receptor kinase activity in dwarf chickens. J. Endocrinol., 126, 67-74.

Hansen L.H., Abrahamsen N., Nishimura E., 1995. Glucagon receptor mRNA distribution in rat tissues. Peptides, 16, 1163-1166.

Hanson R.W., Ballard F.J., 1967. The relative significance of acetate and glucose as precursors for lipid synthesis in liver and adipose tissue from ruminants. Biochem. J., 105, 529536.

Hardie D.G., 2011. Sensing of energy and nutrients by AMP-activated protein kinase. Am. J. Clin. Nutr., 93, 891S-896.

Harvey S., Scanes C.G., Chadwick A., Bolton N.J., 1978. Influence of fasting, glucose and insulin on the levels of growth hormone and prolactin in the plasma of the domestic fowl (Gallus domesticus). J. Endocrinol., 76, 501-506.

Hazelwood R.L., 1984. Pancreatic hormones, insulin/glucagon molar ratios, and somatostatin as determinants of avian carbohydrate metabolism. J. Exp. Zool., 232, 647-652.

Hazelwood R.L., 1986. Carbohydrate metabolism. Sturkie P.D. (Ed). Avian physiology $4^{\text {th }}$ Ed., Cornell University Press, NewYork, USA, 303-325.

Hazelwood R.L., Lorenz F.W., 1959. Effects of fasting and insulin on carbohydrate metabolism of the domestic fowl. Am. J. Physiol., 197, 47-51.

Herault F., Saez G., Robert E., Al Mohammad A., Davail S., Chartrin P., Baeza E., Diot C., 2010. Liver gene expression in relation to hepatic steatosis and lipid secretion in two duck species. Anim. Genet., 41, 12-20.

Horton J.D., Goldstein J.L., Brown M.S., 2002. SREBPs: activators of the complete program of cholesterol and fatty acid synthesis in the liver. J. Clin. Invest., 109, 1125-1131.
Hutchinson D.S., Summer R.J., Gibbs M.E., 2008. Energy metabolism and memory processing: Role of glucose transport and glycogen in responses to adrenoceptor activation in the chicken. Brain Res. Bull., 76, 224-234.

Issad T., Kuo M., 2008. O-GlcNAc modification of transcription factors, glucose sensing and glucotoxicity. Trends Endocrinol. Metab., $19,380-389$.

Iynedjian P.B., 2009. Molecular physiology of mammalian glucokinase. Cell Mol. Life Sci., 66, 27-42.

Jlali M., Gigaud V., Métayer-Coustard S., Sellier N., Tesseraud S., Le Bihan-Duval E., Berri C., 2012. Modulation of glycogen and breast meat processing ability by nutrition in chickens: Effect of crude protein level in 2 chicken genotypes. J. Anim. Sci., 90, 447-455.

Jørgensen S.B., Nielsen J.N., Birk J.B., Olsen G.S., Viollet B., Andreelli F., Schjerling P., Vaulont S., Hardie D.G., Hansen B.F., Richter E.A., Wojtaszewski J.F., 2004. The alpha2-5'AMP-activated protein kinase is a site 2 glycogen synthase kinase in skeletal muscle and is responsive to glucose loading. Diabetes, 53, 3074-3081.

Joseph J., Dandekar D.S., Ramachandran A.V., 1996. Dexamethasone-induced alterations in glucose tolerance and, insulin, glucagon and adrenaline responses during the first month in White Leghorn chicks. Br. Poult. Sci., 37, 665-676.

Kanno H., 2000. Hexokinase: gene structure and mutations. Baillieres Best Pract. Res. Clin. Haematol., 13, 83-88.

King D.L., Hazelwood R.L., 1976. Regulation of avian insulin secretion by isolated perfused chicken pancreas. Am. J. Physiol., 231, 1830-1839.

Klandorf H., Probert I.L., Iqbal M., 1999. In the defence against hyperglycamiea: an avian strategy. World's Poult. Sci. J., 55, 251-268

Kono T., Nishida M., Nishiki Y., Seki Y., Sato K., Akiba Y., 2005. Characterisation of glucose transporter (GLUT) gene expression in broiler chickens. Br. Poult. Sci., 46, 510-515.

Langslow D.R., 1976. The half-life of bovine and chicken insulin in chicken plasma. Gen. Comp. Endocrinol., 29, 423-425.

Langslow D.R., Hales C.N., 1969. Lipolysis in chicken adipose tissue in vitro. J. Endocrinol., 43, 285-294.

Le Bihan-Duval E., Debut M., Berri C.M., Sellier N., Sante-Lhoutellier V., Jego Y., Beaumont C., 2008a. Chicken meat quality: genetic variability and relationship with growth and muscle characteristics. BMC Genet., 9, 53 .

Le Bihan-Duval E., Berri C., Pitel F., Nadaf J., Sibut V., Gigaud V., Duclos M., 2008 b. Approches combinées de génomique positionnelle et expressionnelle pour l'étude des gènes contrôlant la qualité de la viande chez les volailles. INRA Prod. Anim., 21, 159-166.

Leclercq B., Simon J., Ricard F.H., 1987. Effects of selection for high and low plasma glucose concentration in chickens. Br. Poult. Sci., 28, 557-566.

Leclercq B., Simon J., Karmann H., 1988. Glucagon-insulin balance in genetically lean or fat chickens. Diabete Metab., 14, 641-645.

Legrand P., Hermier D., 1992. Hepatic delta 9 desaturation and plasma VLDL level in genetically lean and fat chickens. Int. J. Obes. Relat. Metab. Disord., 16, 289-294.

Leveille G.A., O'Hea E.K., Chakbabarty K., 1968. In vivo lipogenesis in the domestic chicken. Proc. Soc. Exp. Biol. Med., 128, 398401.

Longnus S.L., Wambolt R.B., Parsons H.L., Brownsey R.W., Allard M.F., 2003. 5-Aminoimidazole-4-carboxamide 1-beta -D-ribofuranoside (AICAR) stimulates myocardial glycogenolysis by allosteric mechanisms. Am. J. Physiol. Regul. Integr. Comp. Physiol., 284, R936-944.

Lu J.W., McMurtry J.P., Coon C.N., 2007. Developmental changes of plasma insulin, glucagon, insulin-like growth factors, thyroid hormones, and glucose concentrations in chick embryos and hatched chicks. Poult. Sci., 86, 673-683.

Mameri H., Dupont J., Joubert R., Collin A. Crochet S., Cailleau-Audouin E., Tesseraud S. Métayer-Coustard S., 2010. Mechanisms regulating the peripheral utilisation of glucose: involvement of AMPK. 3. Int. EAAP Symp. Energ. Prot. Metabol. Nutr., Parma, Italy, EAAP Publ., 127, 259-260.

Manolescu A.R., Witkowska K., Kinnaird A., Cessford T., Cheeseman C., 2007 Facilitated hexose transporters: new perspectives on form and function. Physiology, 22, 234-240.

Matschinsky F.M., 2009. Assessing the potential of glucokinase activators in diabetes therapy. Nat. Rev. Drug Discov., 8, 399-416.

Métayer S., Seiliez I., Collin A., Duchêne S. Mercier Y., Geraert P.A., Tesseraud S., 2008. Mechanisms through which sulfur amino acids control protein met Mechanisms through which sulfur amino acids control protein metabolism and oxidative status. J. Nutr. Biochem., 19, 207-215.

Miyamoto L., Toyoda T., Hayashi T., Yonemitsu S., Nakano M., Tanaka S., Ebihara K., Masuzaki H., Hosoda K., Ogawa Y., Inoue G., Fushiki T., Nakao K., 2007. Effect of acute activation of 5'-AMP-activated protein kinase on glycogen regulation in isolated rat skeletal muscle. J. Appl. Physiol., 102, 1007-1013.

Modak M.A., Datar S.P., Bhonde R.R., Ghaskadbi S.S., 2007. Differential susceptibility of chick and mouse islets to streptozotocin and its co-relation with islet antioxidant status. J. Comp. Physiol. B, 177, 247-257.

Moran E.T. Jr., 2007. Nutrition of the developing embryo and hatchling. Poult. Sci., 86, 1043-1049.

Mourot J., Kouba M., 1999. Development of intra- and intermuscular adipose tissue in growing large white and Meishan pigs. Reprod. Nutr. Dev., 39, 125-32.

Nadaf J., Pitel F., Gilbert H., Duclos M.J., Vignoles F., Beaumont C., Vignal A., Porter T.E., Cogburn L.A., Aggrey S.E., Simon J., Le Bihan-Duval E., 2009. QTL for several metabolic traits map to loci controlling growth and body composition in an F2 intercross between high- and low-growth chicken lines. Physiol. Genomics, 38, 241-249.

Nijdam E., Lambooij E., Nabuurs M.J., Decuypere E., Stegeman J.A., 2006. Influences of feeding conventional and semisynthetic diets and transport of broilers on weight gain, digestive tract mass, and plasma hormone and metabolite concentrations. Poult. Sci., 85, 1652-1629. 
Nur T., Sela I., Webster N.J., Madar Z., 1995. Starvation and refeeding regulate glycogen synthase gene expression in rat liver at the posttranscriptional level. J. Nutr., 125, 2457 2462.

Panserat S., Blin C., Medale F., PlagnesJuan E., Breque J., Krishnamoorthy J., Kaushik S., 2000. Molecular cloning, tissue distribution and sequence analysis of complete glucokinase cDNAs from gilthead seabream (Sparus aurata), rainbow trout (Oncorhynchus mykiss) and common carp (Cyprinus carpio). Biochim. Biophys. Acta, 1474, 61-69.

Proszkowiec-Weglarz M., Richards M.P., Humphrey B.D., Rosebrough R.W., McMurtry J.P., 2009. AMP-activated protein kinase and carbohydrate response element binding protein: a study of two potential regulatory factors in the hepatic lipogenic program of broiler chickens. Comp. Biochem. Physiol. B Biochem. Mol. Biol., 154, 68-79.

Pulikanti R., Peebles E.D., Keirs R.W. Bennett L.W., Keralapurath M.M., Gerard P.D., 2010. Pipping muscle and liver metabolic profile changes and relationships in broiler embryos on days 15 and 19 of incubation. Poult. Sci., 89, 860-865.

Renner R., Elcombe A.M., 1967. Protein as a carbohydrate precursor in the chick. J. Nutr., 93, 25-30.

Richards M.P., Poch S.M., Coon C.N., Rosebrough R.W., Ashwell C.M., McMurtry J.P., 2003. Feed restriction significantly alters lipogenic gene expression in broiler breeder chickens. J. Nutr., 133, 707-715.

Richards M.P., Proszkowiec-Weglarz M. Rosebrough R.W., McMurtry J.P., Angel R., 2010. Effects of early neonatal development and delayed feeding immediately post-hatch on the hepatic lipogenic program in broiler chicks. Comp. Biochem. Physiol. B Biochem. Mol. Biol., 157, 374-388.

Rideau N., 1988. Insulin secretion in birds Leanness in domestic birds.Genetic, metabolic and hormonal aspects. Leclercq B., Whitehead C.C. (Eds). Butterworths and Co. Ltd-INRA, 269-294.

Rideau N., 1998. Peculiarities of insulin secretion in chickens. Ann. N.Y. Acad. Sci., 839, 162-165.

Rideau N., Simon J., Leclercq B., 1986. Further characterization of insulin secretion from the perfused duodenum-pancreas of chicken: a comparison of insulin release in chickens selected for high and low abdominal fat content. Endocrinology, 119, 2635-2341.

Rideau N., Berradi H., Skiba-Cassy S., Panserat S., Cailleau-Audouin E., Dupont J., 2008. Induction of glucokinase in chicken liver by dietary carbohydrates. Gen. Comp. Endocrinol., 158, 173-177.

Rideau N., Derouet M., Grimsby J., Simon J., 2010. Glucokinase activation induces potent hypoglycemia without recruiting insulin and inhibits food intake in chicken. Gen. Comp. Endocrinol., 169, 276-283.

Riesenfeld G., Geva A., Hurwitz S., 1982. Glucose homeostasis in the chicken. J. Nutr., 112, 2261-2266.

Rosebrough R.W., Russell B.A., Richards M.P., 2008. Short term changes in the expression of lipogenic genes in broilers (Gallus gallus). Comp. Biochem. Physiol. A. Mol. Integr. Physiol., 149, 389-395.
Ruffier L., Simon J., Rideau N., 1998. Isolation of functional glucagon islets of Langerhans from the chicken pancreas. Gen. Comp. Endocrinol., 112, 153-162.

Saadoun A., Leclercq B., 1983. Comparison of in vivo fatty acid synthesis of the genetically lean and fat chickens. Comp. Biochem. Physiol. B Biochem. Mol. Biol., 75, 641-644.

Saadoun A., Leclercq B., 1986. In vivo lipogenesis in genetically fat and lean chickens of various ages. Comp. Biochem. Physiol. B Biochem. Mol. Biol., 83, 607-611.

Saadoun A., Simon J., Williams J., Leclercq B., 1988. Levels of insulin, corticosterone, T3, T4 and insulin sensitivity in fat and lean chickens. Diabete Metab., 14, 97-103.

Saez G., Baeza E., Davail S., Durand D., Bauchart D., Gruffat D., 2009. Hepatic metabolism of glucose and linoleic acid varies in relation to susceptibility to fatty liver in ad libitum-fed Muscovy and Pekin ducks. Br. J. Nutr., 101, 510-517.

Scanes C.G., 2008. Perspectives on analytical techniques and standardization. Poult. Sci., 87, 2175-2177.

Scanes C.G., 2009. Perspectives on the endocrinology of poultry growth and metabolism. Gen. Comp. Endocrinol., 163, 24-32.

Seki Y., Sato K., Kono T., Abe H., Akiba Y., 2003. Broiler chickens (Ross strain) lack insulin-responsive glucose transporter GLUT4 and have GLUT8 cDNA. Gen. Comp. Endocrinol., 133, 80-87.

Seki Y., Sato K., Akiba Y., 2005. Changes in muscle mRNAs for hexokinase, phosphofructokinase- 1 and glycogen synthase in acute and persistent hypoglycemia induced by tolbutamide in chickens. Comp. Biochem. Physiol. B Biochem. Mol. Biol., 142, 201-218.

Sibut V., Le Bihan-Duval E., Tesseraud S., Godet E., Bordeau T., Cailleau-Audouin E., Chartrin P., Duclos M.J., Berri C., 2008. Adenosine monophosphate-activated protein kinase involved in variations of muscle glycogen and breast meat quality between lean and fat chickens. J. Anim. Sci., 86, 2888-2896.

Sibut V., Hennequet-Antier C., Le BihanDuval E., Marthey S., Duclos M.J., Berri C., 2011. Identification of differentially expressed genes in chickens differing in muscle glycogen content and meat quality. BMC Genomics, 12,112 .

Simon J., 1989. Chicken as a useful species for the comprehension of insulin action. Crit. Rev. Poult. Biol., 2, 121-148.

Simon J., Rosselin G., 1979. Effect of intermittent feeding on glucose-insulin relationship in the chicken. J. Nutr., 109, 631-641.

Simon J., Leclercq B., 1982. Longitudinal study of adiposity in chickens selected for high or low abdominal fat content: further evidence of a glucose-insulin imbalance in the fat line. J. Nutr., 112, 1961-1973.

Simon J., Rideau N., Taouis M., Dupont J., 2011. Plasma insulin levels are rather similar in chicken and rat. Gen. Comp. Endocrinol., 171, 267-268.

Sinsigalli N.A., McMurtry J.P., Cherry J.A., Siegel P.B., 1987. Glucose tolerance, plasma insulin and immunoreactive glucagon in chickens selected for high and low body weight. J. Nutr., 117, 941-7.
Stevens L., 2004. Avian Biochemistry and Molecular Biology. Cambridge University Press, 288p.

Strandholm J.J., Cardenas J.M., Dyson R.D., 1975. Pyruvate kinase isozymes in adult and fetal tissues of chicken. Biochemistry, 14, 2242-2246.

Sunny N.E., Bequette B.J., 2011. Glycerol is a major substrate for glucose, glycogen, and nonessential amino acid synthesis in late-term chicken embryos. J. Anim. Sci., 89, 39453953.

Taouis M., Derouet M., Chevalier B., Simon J., 1993. Corticosterone effect on insulin receptor number and kinase activity in chicken muscle and liver. Gen. Comp. Endocrinol., 89, 167175.

Tesseraud S., Métayer S., Duchêne S., Bigot K., Grizard J., Dupont J., 2007. Regulation of protein metabolism by insulin: value of different approaches and animal models. Domest. Anim. Endocrinol., 33, 123-142.

Tesseraud S., Métayer-Coustard S., Collin A., Seiliez I., 2009. Role of sulfur amino acids in controlling nutrient metabolism and cell functions: implications for nutrition. Br. J. Nutr., 101, 1132-1139.

Thomas-Delloye V., Marmonier F., Duchamp C., Pichon-Georges B., Lachuer J., Barré H., Crouzoulon G., 1999. Biochemical and functional evidences for a GLUT-4 homologous protein in avian skeletal muscle. Am. J. Physiol., 277, R1733-1740.

Thorens B., Mueckler M., 2010. Glucose transporters in the $21^{\text {st }}$ Century. Am. J. Physiol. Endocrinol. Metab., 298, E141-145.

Tinker D.A., Brosnan J.T., Herzberg G.R., 1986. Interorgan metabolism of amino acids, glucose, lactate, glycerol and uric acid in the domestic fowl (Gallus domesticus). Biochem. J., 240, 829-836.

Tokushima Y., Takahashi K., Sato K., Akiba Y., 2005. Glucose uptake in vivo in skeletal muscles of insulin-injected chicks. Comp. Biochem. Physiol. B Biochem. Mol. Biol., 141, 43-48.

Touchburn S., Simon J., Leclercq B., 1981. Evidence of a glucose-insulin imbalance and effect of dietary protein and energy level in chickens selected for high abdominal fat content. J. Nutr., 111, 325-335.

Tremblay F., Lavigne C., Jacques $H$. Marette A., 2007. Role of dietary proteins and amino acids in the pathogenesis of insulin resistance. Annu. Rev. Nutr., 27, 293-310.

Uni Z., Ferket P.R., Tako E., Kedar O., 2005. In ovo feeding improves energy status of lateterm chicken embryos. Poult. Sci., 84, 764-770.

Wang M.Y., Tsai M.Y., Wang C., 1994 Identification of chicken liver glucose transporter. Arch. Biochem. Biophys., 310, 172-179.

Watford M., Hod Y., Chiao Y.B., Utter M.F., Hanson R.W., 1981. The unique role of the kidney in gluconeogenesis in the chicken. The significance of a cytosolic form of phosphoenolpyruvate carboxykinase. J. Biol. Chem. 256,10023-10027.

Wellen K.E., Hatzivassiliou G., Sachdeva U.M., Bui T.V., Cross J.R., Thompson C.B., 2009. ATP-citrate lyase links cellular metabolism to histone acetylation. Science, 324, 1076-1080.

Wilson J.E., 2003. Isozymes of mammalian hexokinase: structure, subcellular localization 
and metabolic function. J. Exp. Biol., 206, 2049-2057.

Yu J., Auwerx J., 2009. The role of sirtuins in the control of metabolic homeostasis. Ann. N.Y. Acad. Sci., 1173, E10-19.
Zhai W., Gerard P.D., Pulikanti R., Peebles E.D., 2011. Effects of in ovo injection of carbohydrates on embryonic metabolism, hatchability, and subsequent somatic characteristics of broiler embryos and hatchlings. Poult Sci., 90, 2134-2143.
Zhang Y., Yin L., Hillgartner F.B., 2003. SREBP-1 integrates the actions of thyroid hormone, insulin, cAMP, and medium-chain fatty acids on ACCalpha transcription in hepatocytes. J. Lipid Res., 44, 356-368.

\title{
Résumé
}

Les Oiseaux ont développé des mécanismes adaptatifs originaux leur assurant un métabolisme énergétique actif caractérisé par une température et une glycémie basales élevées $\left(42^{\circ} \mathrm{C}\right.$ et $\left.2 \mathrm{~g} / \mathrm{L}\right)$. Les travaux réalisés en majorité sur les espèces d'intérêt agronomique (poulet, canard) font ressortir une régulation particulière de l'homéostasie glucidique et notamment du système insulinique, hormone majeure contrôlant le métabolisme. Dans une première partie, nous rapportons quelques données générales concernant les particularités du métabolisme glucidique et de sa régulation par l'insuline chez les espèces avicoles. Dans une deuxième partie, nous présentons les travaux récents concernant la captation de glucose, son utilisation et son stockage par les trois tissus majeurs impliqués dans le maintien de l'homéostasie glucidique à savoir le foie, le muscle et le tissu adipeux. Ces connaissances fondamentales ont pour but d'orienter les programmes de recherche appliquée visant à améliorer la croissance et la qualité des viandes de volailles.

\begin{abstract}
Glucose peripheral utilisation in the chicken and duck: growth and meat quality implications.

Birds have developed original adaptive mechanisms ensuring them an active energy metabolism characterized by a high basal temperature and glycaemia $\left(42^{\circ} \mathrm{C}\right.$ and $\left.2 \mathrm{~g} / \mathrm{L}\right)$. Studies completed mostly on agronomic species (chicken, duck) emphasize a specific regulation of glucose homeostasis. In a first part we report some general data on glucose metabolism characteristics and its regulation by insulin in poultry. In a second part we present recent work concerning glucose uptake, its use and storage by the 3 major tissues implied in glucose homeostasis regulation (liver, muscle and fat). The purpose of this fundamental knowledge is to direct applied programs aimed at improving growth and quality of poultry productions.
\end{abstract}

RIDEAU N., MÉTAYER-COUSTARD S., 2012. Utilisation périphérique du glucose chez le poulet et le canard : implications pour la croissance et la qualité de la viande. INRA Prod. Anim., 25, 4, 337-350. 